\title{
NDICE INSTITUCIONAL
} PARA EL GOBIERNO ABIERTO MUNICIPAL

$$
\text { IIGAM CHILE } 2020
$$

José A. Hernández Bonivento

它

RiL editores
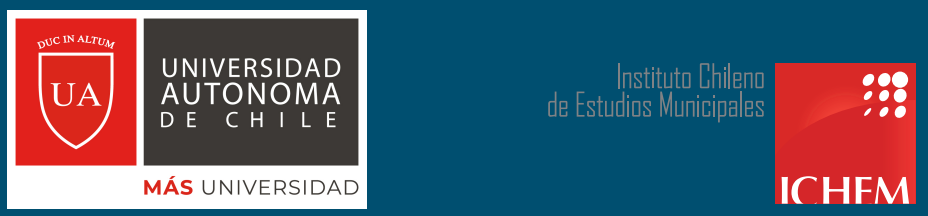


\title{
ÍNDICE INSTITUCIONAL PARA EL GOBIERNO ABIERTO MUNICIPAL
}

IIGAM CHILE 2020

\author{
José A. Hernández Bonivento
}

它

RiL editores 
ÍNDICE INSTITUCIONAL PARA EL GOBIERNO

ABIERTO MUNICIPAL

IIGAM CHILE $\cdot 2021$

Primera edición: agosto de 2021

(c) Universidad Autónoma de Chile, 2021

Registro de Propiedad Intelectual

No 2021-A-5870

(C) RIL@ editores, 2021

SEDE SANTIAGO:

Los Leones 2258

CP 7511055 Providencia

Santiago de Chile

(J) (56) 222238100

ril@rileditores.com·www.rileditores.com

(c) Universidad Autónoma de Chile, 2021

http://ediciones.uautonoma.cl | ediciones@uautonoma.cl

(c) Instituto Chileno de Estudios Municipales (ICHEM), 2021

Facultad de Ciencias Sociales y Humanidades

Universidad Autónoma de Chile

Galvarino Gallardo 1973, Providencia, Santiago

www.ichem.uautonoma.c

Composición e impresión: RIL $®$ editores

Impreso en Chile • Printed in Chile

ISBN 978-956-01-0889-0

ISBN Universidad Autónoma de Chile 978-956-6109-34-1

Derechos reservados.
323.04 Hernández Bonivento, José A.

Índice institucional para el Gobierno Abierto Municipal. IIGAM Chile 2021 / José A. Hernández Bonivento. - - Santiago : ICHEM, Universidad Autónoma de Chile • RIL editores, 2021

44 p. ; $21 \mathrm{~cm}$.

ISBN: 978-956-01-0889-0

GOBIERNO LOCAL-CHILE. 2 MUNICIPIOS-GOBIERNO Y ADMINISTRACIÓNCHILE. 3 MUNICIPIOS-CHILE-PARTICIPACIÓN CIUDADANA 


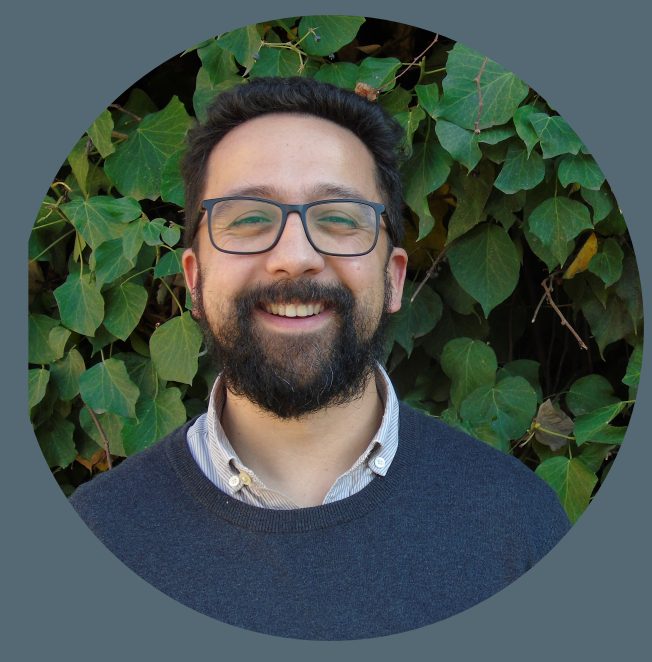

José A. Hernández Bonivento

Este trabajo no hubiera sido posible sin la colaboración y dedicación de José Antonio López, estudiante de Sociología de la Universidad de Chile, y de Nicolás Muñoz, estudiante de Administración Pública de la Universidad Autónoma de Chile, ambos practicantes del ICHEM durante el segundo semestre de 2020, quienes con no poco esfuerzo apoyaron en la recolección de toda la información aquí presentada.

Doctor en Ciencias Políticas y de la Administración, Universidad

Complutense de Madrid. 
Índice

Índice de tablas

Índice de gráficos

01. Presentación

02. Definición conceptual: dimensiones y variables de medición

03. Resultados IIGAm Chile 2020

04. Visión por dimensiones y variables

05. Conclusiones

06. Bibliografía

07. Anexos
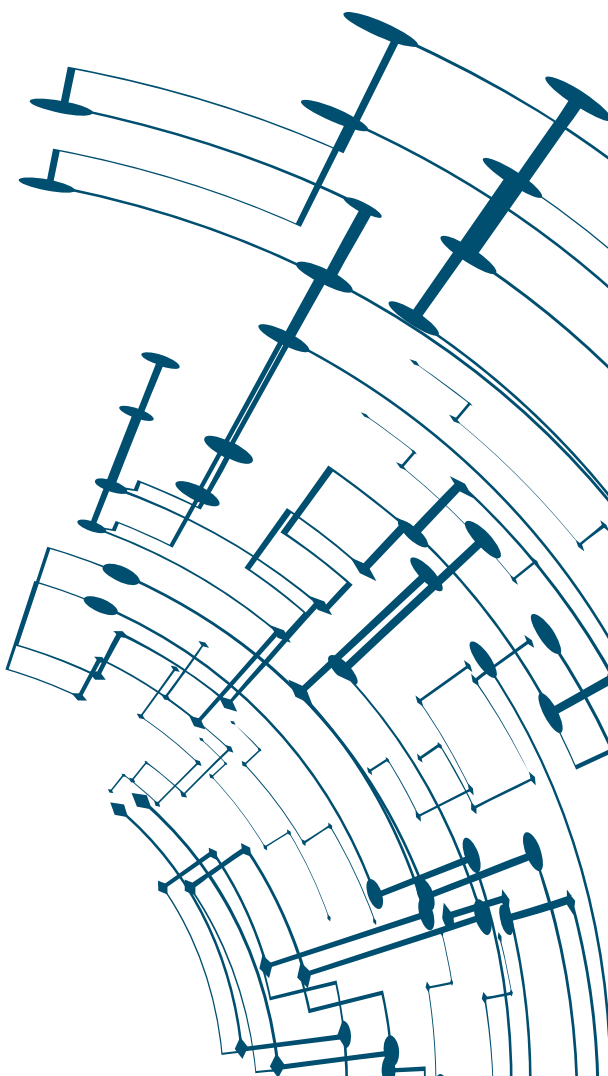
1
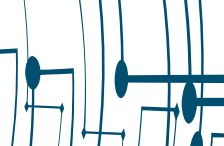

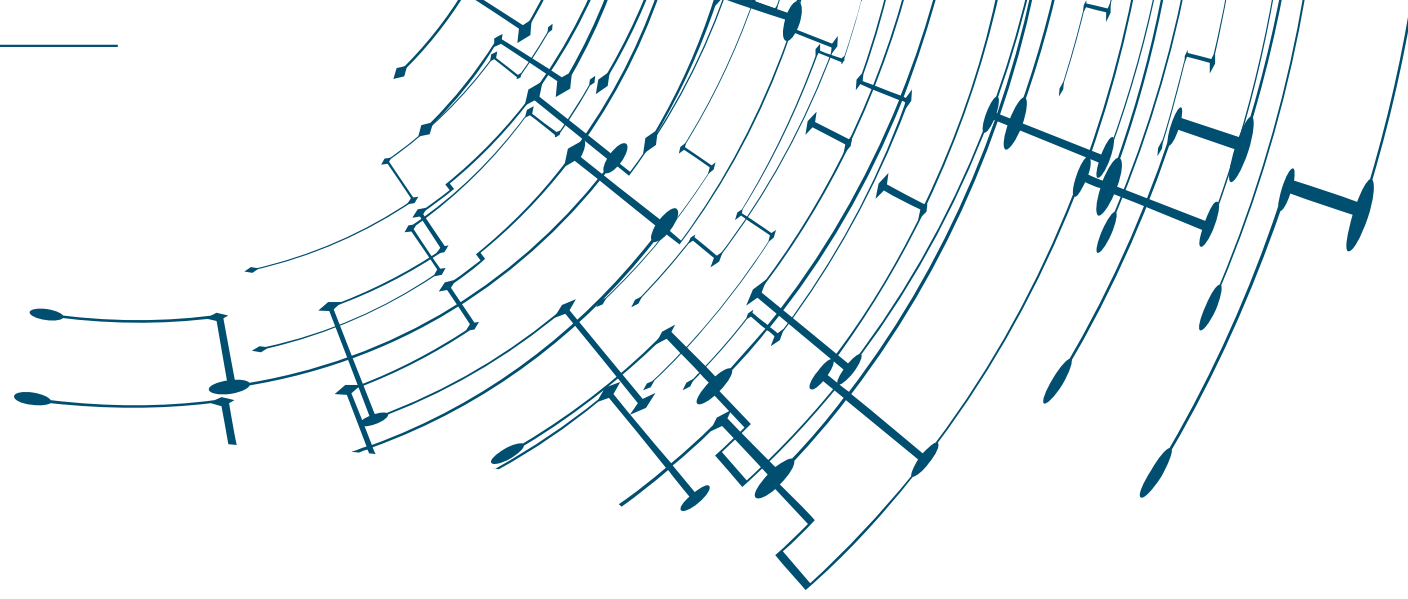




\section{Índice de tablas}

Tabla 1. Criterios de satisfacción - Solicitudes de información a municipalidades Tabla 2. Estructura IIGAM Chile 2020 - Dimensiones, variables y pesos

Tabla 3. IIGAM 2020 - Municipalidades por cuartil

Tabla 4. IIGAM 2020 - 20 mejores puntajes

Tabla 4. IIGAM 2020 - Promedio por dimensión

Tabla 5. IIGAM 2020 - Promedios por región

Tabla 6. IIGAM 2020 - Resultados municipalidades Tipo 1 Subdere

Tabla 7. IIGAM 2020 - Resultados municipalidades Tipo 2 Subdere

Tabla 8. IIGAM 2020 - Resultados municipalidades Tipo 3 Subdere

Tabla 9. IIGAM 2020 - Resultados municipalidades Tipo 4 Subdere

Tabla 10. IIGAM 2020 - Resultados municipalidades Tipo 5 Subdere

\section{Índice de gráficos}

Gráfico 1. IIGAM 2020 - Porcentaje de comunas por cuartil

Gráfico 2. IIGAM 2020 - Promedio por dimensión

Gráfico 3. IIGAM 2020 - Promedios variables por dimensión

Gráfico 4. IIGAM 2020 - Promedios por región

Gráfica 5. IIGAM 2020 por tipología Subdere

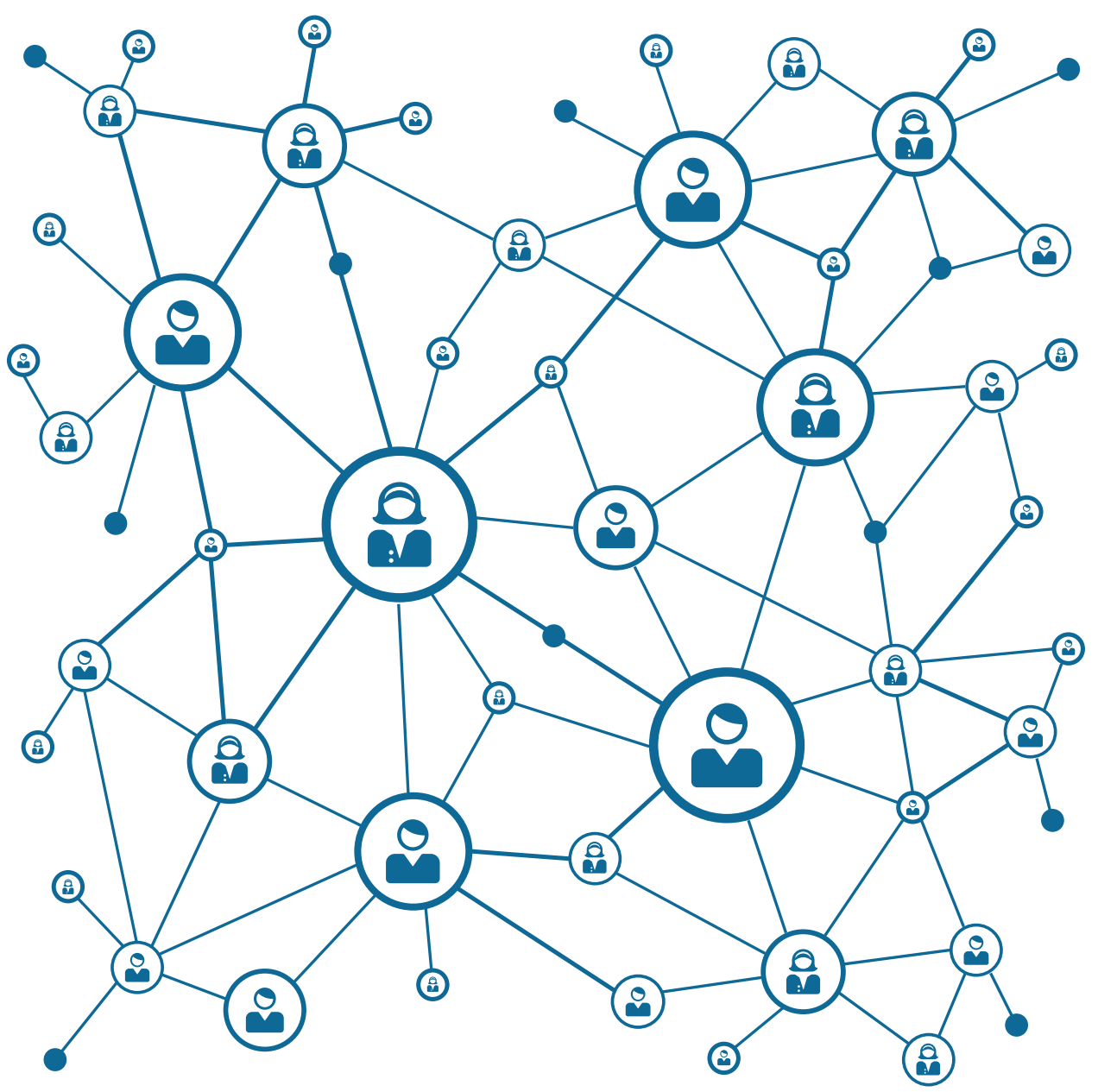




\section{Presentación}




\section{Presentación}

Desde hace un poco más de 10 años, Chile encabeza un proceso de diseño e implementación de marcos jurídicos y estructuras institucionales que buscan, a través de sendos cuerpos legales, la construcción de un gobierno con mayor transparencia, probidad y participación ciudadana en la gestión pública.

Desde el 2008, con la promulgación de la Ley de Acceso a la Información (20.285), siguiendo con la Ley de Asociaciones y Participación Ciudadana en la Gestión Pública (20.500) en el 2011, y las posteriores leyes de Lobby (20.730) y Probidad (2.880) en 2014 y 2015, respectivamente, la legislación chilena ha establecido una serie de mecanismos institucionales a todos los niveles de gobierno, los cuales conllevan no pocas exigencias de cumplimiento y desarrollo para los órganos de la administración del Estado, en especial a las municipalidades.

Por lo mismo, con el objetivo principal de analizar el cumplimiento de dichas entidades frente a las exigencias del marco legal chileno, en el 2016 lanzamos nuestro primer Índice Institucional de Gobierno Abierto Municipal (IIGAM), el cual nos permitió dar una primera mirada a estos temas, desde la lógica de la oferta institucional que prestaban las municipalidades para la transparencia y la participación ciudadana.

Con los años, el IIGAM ha sufrido algunas modificaciones como la inclusión de nuevas variables y nuevas dimensiones, junto a la revisión constante de los mecanismos para la recolección de información, todo ello en pos de construir un instrumento cada vez más robusto y coherente. Este ejercicio de revisión constante nos ha permitido entender algunas tendencias y comprender los aspectos que conlleva una medición del gobierno abierto desde el cumplimiento de normas legales.

Además, esta versión ha contado con insumos de primera mano, a través de encuestas virtuales realizadas a expertos tanto de la sociedad civil como de la academia, tanto para la construcción de las variables como para la asignación de los pesos relativos en la construcción del indicador. Por último, el informe completo fue revisado por las tres direcciones del Consejo para la Transparencia: Dirección de Estudios, Dirección de Fiscalización y Dirección de Promoción, Formación y Vinculación. Agradecemos a quienes se tomaron el tiempo para participar en este proceso.

Cabe mencionar, sin embargo, que como cualquier mecanismo de revisión cuantitativo, es una aproximación desde los datos comunales disponibles a ni- vel nacional que debe ser complementada con visiones más cualitativas y desde la realidad local. Esto es aún más importante cuando buscamos acercarnos a un concepto complejo y relacional, como lo es el gobierno abierto.

En todo caso, después de un gran esfuerzo de recolección de información y análisis de datos, entregamos aquí los resultados de esta nueva medición. Con esto, esperamos hacer un nuevo aporte a la comprensión de la apertura gubernamental y a sus implicancias para el nivel local de gobierno. 
2. Deffinición conceptual: dimensiones y variables de medición 
Para el presente texto, entendemos que el concepto gobierno abierto se relaciona, sobre todo, a una cuestión de acceso (Meijer, Curtin \& Hillebrandt, 2012), donde un gobierno puede considerarse abierto en la medida en que actores externos pueden monitorear e influir en los procesos gubernamentales a través del acceso a la información pública y a los espacios de toma de decisiones (Grimmelikhuijsen \& Feeney, 2016).

Esta visión conceptual nos permite hacer una revisión de los aspectos más formales del gobierno abierto, esto es, la implementación de herramientas, mecanismos o espacios que busquen tanto el acceso a la información pública - generando un acercamiento informado desde la ciudadanía y diversos actores sociales a los asuntos públicos-, como el acceso a la toma de decisiones - entendida como la capacidad ciudadana de expresar su voz, su interés, sus problemas y sus puntos de vista, y que estos tengan alguna incidencia en el actuar gubernamental-.

Partiendo de esta definición, el IIGAM se enfoca en variables que buscan medir la oferta, desde las municipalidades, para el acceso ciudadano a los asuntos locales. Entendemos que es precisamente en el espacio local donde se presentan las mejores oportunidades para la implementación de estrategias de gobernanza abierta, dada la proximidad, tanto física como administrativa, del Estado y la ciudadanía y, por lo mismo, un lugar fundamental para la construcción y consolidación de estrategias de gobierno abierto (Hernández Bonivento, 2017).

Partiendo de la literatura especializada, las versiones anteriores del IIGAM y del marco legal chileno sobre acceso a la información, participación pública y rendición de cuentas, se definieron conjuntos de datos que podríamos utilizar para esta medición. Buscando la validación de pares evaluadores tanto en la selección como en la asignación de pesos relativos de las variables y dimensiones dentro del IIGAM, se realizó una encuesta virtual, la cual fue enviada a las organizaciones que hacen parte de la Red Académica de Gobierno Abierto y de la Red Chilena de Gobierno Abierto, ambas con representación en la Mesa de Gobierno Abierto, mecanismo de diálogo permanente para el diseño, el seguimiento y la evaluación de los Planes Nacionales de Chile ante la Alianza para el Gobierno Abierto ${ }^{1}$. La encuesta estuvo abierta del 5 al 25 de noviembre de 2020. Se recibieron 15 respuestas de diversas organizaciones del país.

Mayor información sobre el proceso chileno ante la Alianza para el Gobierno Abierto, así como de la Mesa de Gobierno Abierto, sus componentes y funciones, en la página web Gobierno Abierto Chile, del Ministerio
Con toda esta información, planteamos para esta nueva versión las siguientes dimensiones del índice, con sus correspondientes variables de medición.

\section{Transparencia Activa}

Como en las dos versiones pasadas, y partiendo de la Ley 20.285 sobre acceso a la información, entendemos la Transparencia Activa como la obligatoriedad de los órganos del Estado de publicar, en sus páginas web y de manera actualizada, la información pública establecida por ley como prioritaria. Desde el año 2012, el Consejo para la Transparencia (CPLT) realiza el Ranking de Transparencia Activa Municipal, mediante el cual fiscaliza el cumplimiento de todas las municipalidades de Chile en cuanto a la información publicada en sus páginas y portales de transparencia. Sin embargo, para el año 2019, el CPLT inició un proceso de renovación de sus procesos de fiscalización, por lo que para esta medición utilizamos los últimos datos manejados en la lógica de ranking municipal, que corresponden al año 2018.

A su vez, y partiendo de los insumos recolectados por nuestra encuesta a expertos, se observa la importancia de no solo cumplir con las disposiciones legales, sino también tomar en cuenta las buenas prácticas implementadas por las municipalidades en temas de transparencia. El mismo CPLT ha realizado mediciones en este sentido, las cuales se han sumado al proceso de fiscalización anual. En la versión del IIGAM de 2018, agregamos las buenas prácticas como puntos extra (ver IIGAM 2018), pero dada la importancia marcada por los encuestados, quienes señalaron que tanto el cumplimiento de la ley como la implementación de buenas prácticas deberían tener pesos similares en una medición, quisimos sumar esta variable a la presente dimensión para todas las municipalidades del país, y no solo como un reconocimiento a algunas pocas, como en la versión anterior.

\section{Acceso a la Información}

Al igual que en las anteriores versiones, este año repetimos esta dimensión basándonos en la obligación de las municipalidades de responder las solicitudes de información realizadas desde la ciudadanía, dentro de los parámetros es-

Secretaría General de la Presidencia: https://www.ogp.gob.cl/ 
tablecidos por la ley. Para ello, siguiendo los parámetros de la metodología de usuario simulado, se realizaron solicitudes de información a todas las municipalidades a través de una pregunta estandarizada, lo que nos permitió generar dos variables de medición.

Por un lado, la variable "tiempo de respuesta", que parte de si la municipalidad entrega la información dentro del rango establecido para hacerlo (20 días hábiles, con posibilidad de prórroga por otros 10 días), si lo hizo con retraso, o si no entregó información alguna. Todo el ejercicio de envío y recepción de información se realizó entre el 1 de julio y el 30 de noviembre de 2020.

Por el otro, la variable "calidad de la respuesta" parte del nivel de satisfacción en cuanto a la respuesta obtenida. Dado que todas las solicitudes se realizaron con la misma pregunta estandarizada, se establecen los siguientes criterios de satisfacción en las respuestas, dependiendo del nivel de detalle y de las evidencias presentadas (tabla 1 ).

\section{Tabla 1. Criterios de satisfacción - Solicitudes de información a municipalidades}

\begin{tabular}{|c|c|c|c|c|}
\hline $\begin{array}{l}\text { Pregunta solicitud } \\
\text { información }\end{array}$ & \multicolumn{4}{|c|}{ Criterios satisfacción pregunta } \\
\hline $\begin{array}{l}\text { ¿Cuáles son las } \\
\text { modalidades, formales }\end{array}$ & No responde & $\begin{array}{c}\text { No } \\
\text { satisfactoria }\end{array}$ & $\begin{array}{c}\text { Poco } \\
\text { satisfactoria }\end{array}$ & Satisfactoria \\
\hline $\begin{array}{l}\text { y específicas, de } \\
\text { participación ciudadana } \\
\text { que han implementado } \\
\text { para que personas y } \\
\text { organizaciones sociales } \\
\text { puedan participar } \\
\text { en políticas, planes, } \\
\text { programas y acciones } \\
\text { del municipio durante } \\
\text { el año 2019? De ser } \\
\text { posible, adjuntar } \\
\text { enlaces o documentos } \\
\text { que evidencien dicha } \\
\text { implementación. }\end{array}$ & $\begin{array}{l}\text { No se recibe } \\
\text { respuesta de } \\
\text { la solicitud de } \\
\text { información. }\end{array}$ & $\begin{array}{l}\text { Se recibe } \\
\text { respuesta, } \\
\text { pero no da } \\
\text { detalle de las } \\
\text { modalidades de } \\
\text { participación } \\
\text { ciudadana. }\end{array}$ & $\begin{array}{l}\text { Se recibe } \\
\text { respuesta con } \\
\text { mecanismos de } \\
\text { participación } \\
\text { ciudadana, } \\
\text { pero sin } \\
\text { evidencias. }\end{array}$ & $\begin{array}{c}\text { Se recibe } \\
\text { respuesta con } \\
\text { mecanismos de } \\
\text { participación } \\
\text { ciudadana y } \\
\text { evidencias, o } \\
\text { acepta la no } \\
\text { implementación. }\end{array}$ \\
\hline
\end{tabular}

FUENTE: elaboración propia

Con esto, se mantiene la rúbrica de evaluación implementada en la primera versión del IIGAM , permitiéndonos una revisión a través de las tres versiones de esta medición.

\section{Probidad y declaraciones de conflicto de interés}

Esta dimensión, implementada por primera vez en el IIGAM 2018, se basa en las declaraciones que, de manera obligatoria, deben presentar tanto alcaldes como concejales sobre los potenciales conflictos de interés que puedan surgir en su labor como autoridades locales (Ley 20.880 de probidad en la función pública). Extrayendo las bases y las diversas declaraciones presentadas por dichas autoridades en la plataforma de información InfoProbidad, para esta versión del IIGAM nos fijamos en el cumplimiento de dichas autoridades a la presentación anual de su declaración de conflicto de interés, la cual debe presentarse durante el mes de marzo de cada año, tanto por alcaldes como por concejales municipales (Art. 5, Ley 20.880).

Dos variables se construyeron con esta información: por una parte, el cumplimiento de la primera autoridad de presentar su declaración anual durante el año 2020 y, por el otro, el porcentaje de concejales que, en cumplimiento de la legislación, realizaron su actualización durante el mismo año.

\section{Participación Pública}

Por último, para esta nueva versión del IIGAM reunimos en una misma dimensión dos conjuntos de variables que, en versiones anteriores, habíamos mantenido separadas: por una parte, la que llamamos Participación Institucional, la cual parte de la revisión de las ordenanzas de participación de todas las municipalidades del país, y, por el otro, la que llamamos Implementación, que parte tanto de las respuestas de las solicitudes de información (como lo hicimos en el IIGAM 2018) y de la revisión de las páginas web de aquellas municipalidades de las que no obtuvimos información a través de dichas solicitudes.

Las variables que surgen de la revisión de las ordenanzas, parten del primer ejercicio que realizamos en el IIGAM 2016, donde se establece como primer dato de medición si dichos documentos recogen los cuatro mecanismos señalados explícitamente en la Ley 20.500: los Consejos Comunales de Organizaciones de la Sociedad Civil (cosoc), las audiencias públicas, las Oficinas de Información, Reclamos y Solicitudes (OIRS) y los plebiscitos comunales.

Una segunda variable fue la revisión de los mecanismos de participación establecidos, aparte de los mencionados anteriormente, y su nivel de incidencia, la cual, partiendo de la escala de participación de la Asociación Internacional de Participación Pública (iap2), dividimos en tres niveles: información y consulta, 
involucramiento y colaboración, y empoderamiento. Uniendo tanto la cantidad de mecanismos propios, como su nivel de incidencia, realizamos una normalización de mínimos y máximos partiendo de un máximo teórico (sumando un mecanismo de información al máximo observado), lo que nos permitió generar una escala de 0 a 1 e integrarlo a la presente medición.

En cuanto a las variables de implementación de mecanismos de participación, los datos fueron recolectados a través de las solicitudes de información (para aquellas municipalidades que entregaron información satisfactorio o poco satisfactoria) y a través de la revisión de sus páginas web (para aquellas que no entregaron información sobre este particular en las solicitudes realizadas). Una vez recolectados estos datos, se realizó el mismo ejercicio de normalización de mínimos y máximos realizado para la revisión de las ordenanzas de participación municipal.

Después del proceso de definición de dimensiones y variables, presentamos a continuación la estructura completa del IIGAM 2020, incluyendo los pesos asignados tanto a cada dimensión como a cada variable dentro de su dimensión (tabla 2). Para realizar esta asignación de pesos a las dimensiones y variables, nos basamos tanto en los estudios anteriores como en la encuesta virtual a los expertos de la academia y la sociedad civil.

\section{Tabla 2. Estructura IIGAM Chile 2020 - Dimensiones, variables y pesos}

\begin{tabular}{|c|c|c|c|c|}
\hline Dimensiones & $\begin{array}{l}\text { Peso } \\
\text { IIGAM }\end{array}$ & Variables & Dato & $\begin{array}{c}\text { Peso en } \\
\text { dimensión }\end{array}$ \\
\hline \multirow{2}{*}{ Transparencia } & \multirow{2}{*}{$25 \%$} & Cumplimiento Ley 20.285 & Ranking CPLT - 2018 & $50 \%$ \\
\hline & & Buenas prácticas & Transparencia proactiva & $50 \%$ \\
\hline \multirow{2}{*}{ Probidad } & \multirow{2}{*}{$25 \%$} & Declaraciones alcalde & InfoProbidad & $50 \%$ \\
\hline & & Declaraciones concejales & InfoProbidad & $50 \%$ \\
\hline \multirow{2}{*}{$\begin{array}{l}\text { Acceso a la } \\
\text { información }\end{array}$} & \multirow{2}{*}{$25 \%$} & Tiempo de respuesta & $\begin{array}{l}\text { Solicitudes de } \\
\text { información }\end{array}$ & $50 \%$ \\
\hline & & Calidad de respuesta & $\begin{array}{l}\text { Solicitudes de } \\
\text { información }\end{array}$ & $50 \%$ \\
\hline \multirow{3}{*}{$\begin{array}{l}\text { Participación } \\
\text { pública }\end{array}$} & \multirow{3}{*}{$25 \%$} & $\begin{array}{c}\text { Mecanismos } \\
\text { institucionales }\end{array}$ & $\begin{array}{l}\text { Ordenanzas de } \\
\text { participación }\end{array}$ & $20 \%$ \\
\hline & & Mecanismos propios & $\begin{array}{l}\text { Ordenanzas de } \\
\text { participación }\end{array}$ & $30 \%$ \\
\hline & & $\begin{array}{l}\text { Incidencia mecanismos } \\
\text { implementados }\end{array}$ & $\begin{array}{l}\text { Solicitudes de } \\
\text { información y revisión } \\
\text { páginas web }\end{array}$ & $50 \%$ \\
\hline
\end{tabular}

FUENTE: elaboración propia
Como se observa, el IIGAM 2020 asigna a cada una de las dimensiones el mismo peso dentro de la construcción del índice, debido en parte por continuar con la lógica del IIGAM 2018, que buscaba evitar sesgos discrecionales, pero en su mayoría por la valoración realizada por los expertos, quienes en promedio dieron valoraciones casi iguales tanto a las dimensiones como a las variables. La única excepción se dio en la dimensión Participación Pública, donde todos valoraron los niveles de incidencia de los mecanismos de participación muy por encima de las dos variables medidas a través de las ordenanzas, algo que reflejamos al distribuir sus pesos al interior de esta dimensión. 
3. Resultados IIGAM Chile 2020 
Al revisar los datos de esta versión, encontramos que, a pesar de ser pocas las municipalidades con un nivel alto de cumplimiento (25 de 345), la gran mayoría de las municipalidades del país se encuentra en un desarrollo medio-alto de la oferta institucional para el gobierno abierto, con casi un $60 \%$ de municipalidades en el segundo cuartil, entre el $50 \%$ y el $75 \%$ de cumplimiento. Además, es una muy buena noticia ver que solo el $1 \%$ de las municipalidades chilenas tienen un cumplimiento menor al $25 \%$, encontrándose en claro rezago a nivel nacional (tabla 3 y gráfico 1$)$.

\section{Tabla 3. IIGAM 2020 - Municipalidades por cuartil}

\begin{tabular}{|c|c|c|c|c|}
\hline & $>75 \%$ & $75 \%-50 \%$ & $50 \%-25 \%$ & $<25 \%$ \\
\hline Porcentaje & $7 \%$ & $59 \%$ & $33 \%$ & $1 \%$ \\
\hline No. de comunas & 25 & 202 & 113 & 5 \\
\hline
\end{tabular}

FUENTE: elaboración propia

\section{Gráfico 1. IIGAM 2020 - Porcentaje de comunas por cuartil}

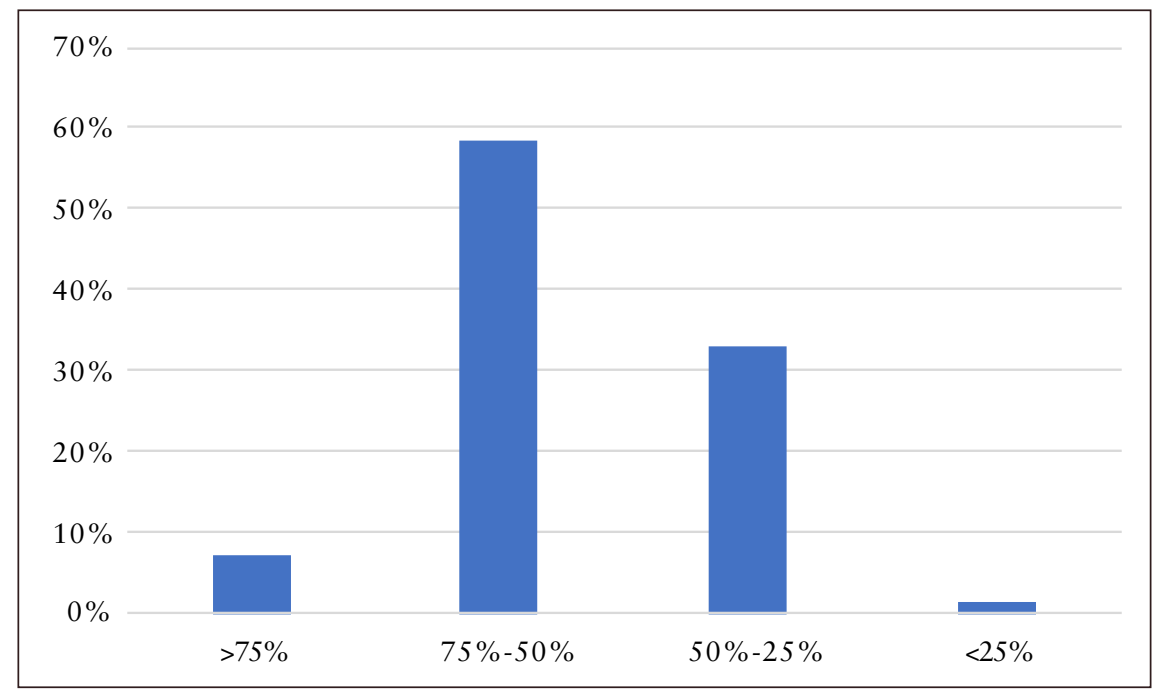

FUENTE: elaboración propia

Como en las dos mediciones pasadas, dentro de los primeros 20 casos de alto cumplimiento e implementación encontramos una gran variedad de comunas, de todas partes de Chile y con variado nivel de desarrollo, con casos muy urbanos y densamente poblados hasta comunas que se sitúan entre las más rurales y periféricas del país. Algunas de ellas repiten en los primeros lugares del IIGAM 2018, como es el caso de La Cisterna, La Serena, Purranque, Fresia y Pucón. Como en las versiones de 2016 y de 2018, estos resultados parecen demostrar que el desarrollo de mecanismos de participación, probidad y transparencia poco dependen del nivel de desarrollo comunal, sino de aspectos informales y propios de cada municipalidad (tabla 4). 
Tabla 4. IIGAM 2020 - 20 mejores puntajes

\begin{tabular}{|c|c|c|c|c|c|}
\hline Municipalidad & $\begin{array}{c}\text { Transparencia } \\
\text { Activa }\end{array}$ & $\begin{array}{c}\text { Acceso } \\
\text { Información }\end{array}$ & Probidad & $\begin{array}{c}\text { Participación } \\
\text { Pública }\end{array}$ & $\begin{array}{c}\text { IIGAM } \\
2,20\end{array}$ \\
\hline La Cisterna & 0,89 & 1,00 & 0,81 & 0,60 & 0,82 \\
\hline Santa Juana & 0,50 & 1,00 & 1,00 & 0,77 & 0,82 \\
\hline Laja & 0,84 & 1,00 & 0,75 & 0,60 & 0,80 \\
\hline Purranque & 0,73 & 1,00 & 1,00 & 0,46 & 0,80 \\
\hline Peñalolén & 0,64 & 1,00 & 0,95 & 0,59 & 0,80 \\
\hline Concepción & 0,62 & 1,00 & 0,85 & 0,69 & 0,79 \\
\hline Pedro Aguirre Cerda & 0,65 & 1,00 & 0,88 & 0,63 & 0,79 \\
\hline Cochrane & 0,79 & 1,00 & 0,83 & 0,53 & 0,79 \\
\hline La Serena & 0,77 & 1,00 & 0,75 & 0,61 & 0,78 \\
\hline Traiguén & 0,63 & 1,00 & 1,00 & 0,50 & 0,78 \\
\hline Lo Barnechea & 0,86 & 1,00 & 0,75 & 0,50 & 0,78 \\
\hline Navidad & 0,63 & 0,83 & 1,00 & 0,63 & 0,77 \\
\hline Pucón & 0,70 & 1,00 & 1,00 & 0,37 & 0,77 \\
\hline Huechuraba & 0,77 & 1,00 & 0,92 & 0,37 & 0,76 \\
\hline Lo Espejo & 0,73 & 1,00 & 0,75 & 0,57 & 0,76 \\
\hline Tucapel & 0,46 & 1,00 & 1,00 & 0,57 & 0,76 \\
\hline Molina & 0,83 & 1,00 & 0,83 & 0,36 & 0,76 \\
\hline Fresia & 0,55 & 1,00 & 0,92 & 0,55 & 0,75 \\
\hline Caldera & 0,43 & 1,00 & 1,00 & 0,58 & 0,75 \\
\hline San Nicolás & 0,45 & 1,00 & 1,00 & 0,55 & 0,75 \\
\hline
\end{tabular}

FUENTE: elaboración propia 
4. Visión por dimensiones y variables 


\section{Visión por dimensiones y variables}

Al revisar los datos por dimensión, resulta evidente un mayor equilibrio entre las cuatro dimensiones de esta medición. Esto se debe, en gran parte, a los cambios realizados en la construcción del presente índice, para integrar las antiguas dimensiones de Participación Institucional e Implementación en una sola de Participación Pública, así como la vinculación de la variable de transparencia proactiva dentro de la dimensión Transparencia, lo que le entrega una fuente relevante de información que la complementa, más allá del ranking de transparencia activa. Con esto, se observa una mayor robustez del instrumento, además de una mayor coherencia conceptual en el análisis de datos.

Ahora, aun con los cambios realizados, esta nueva versión detecta también, como las anteriores de 2016 y de 2018, un claro rezago de la variable Participación Ciudadana, con un promedio de cumplimiento del 37\%, frente al $71 \%$ de la dimensión Acceso a la Información. A su vez, se evidencia un descenso claro en la variable Transparencia Activa, esperable por haber ingresado una nueva variable que mide buenas prácticas más que cumplimiento formal (tabla 5 y gráfico 2).

\section{Tabla 4. IIGAM 2020 - Promedio por dimensión}

\begin{tabular}{|c|c|}
\hline \multicolumn{2}{|c|}{ Dimensiones } \\
\hline Transparencia & $54 \%$ \\
\hline Acceso a la Información & $71 \%$ \\
\hline Probidad & $60 \%$ \\
\hline Participación Pública & $37 \%$ \\
\hline
\end{tabular}

FUENTE: elaboración propia

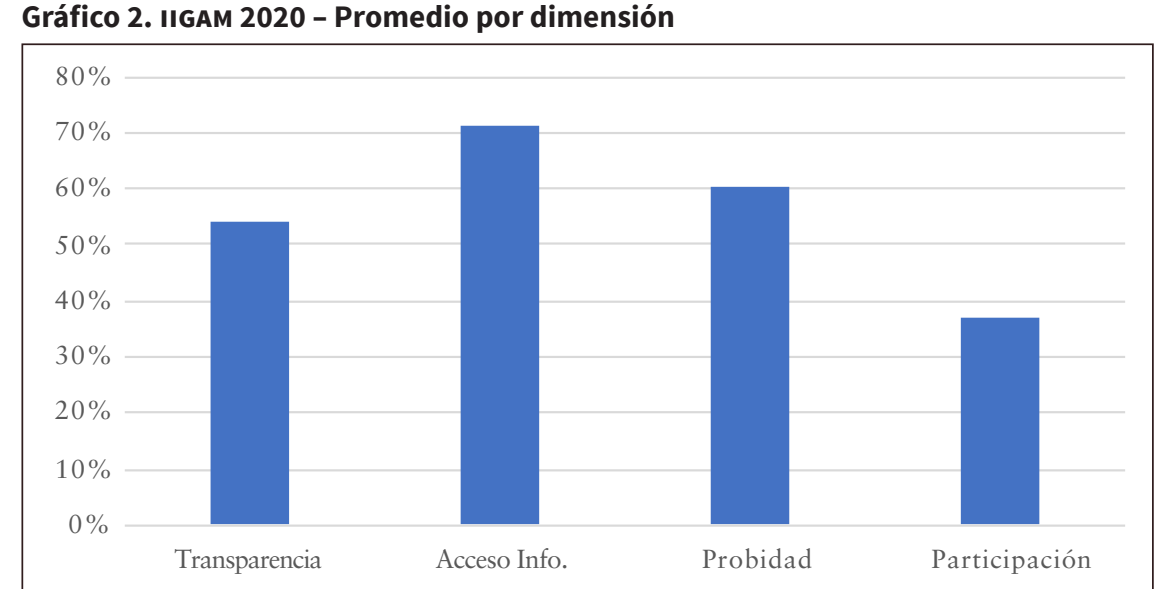

FUENTE: elaboración propia

Además, al observar directamente las variables que componen cada dimensión, se evidencia que las dimensiones con promedios más altos (Acceso a la Información y Probidad) son, precisamente, las que se centran principalmente en variables de cumplimiento legal, mientras que aquellas variables que integran el cumplimiento con las iniciativas locales, sea a través de buenas prácticas en transparencia, o por medio de mecanismos propios de participación e incidencia ciudadana, se encuentran más abajo en sus promedios a nivel nacional (gráfico 3). 


\section{Gráfico 3. IIGAM 2020 - Promedios variables por dimensión}

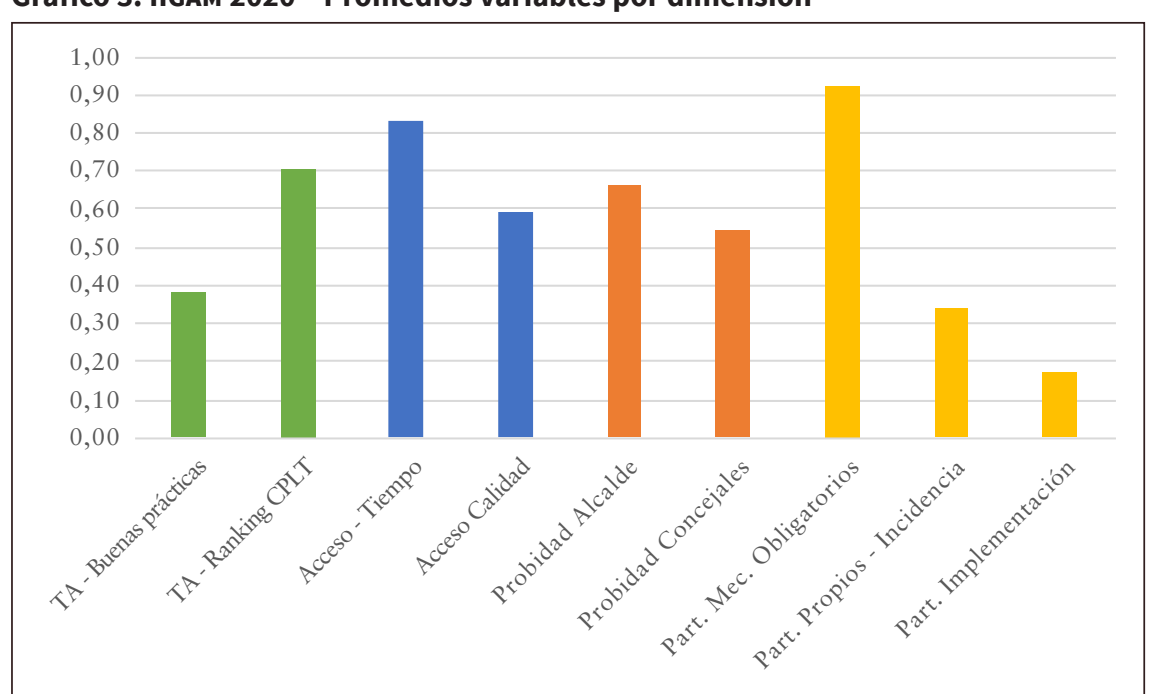

FUENTE: elaboración propia

La dimensión donde más se refleja esta marcada dicotomía entre cumplimiento formal y desarrollo de iniciativas propias es, como en las versiones anteriores de IIGAM , en Participación Pública. Aquí se observa que, a pesar que la altísima mayoría de municipalidades cumplen fielmente con tener una ordenanza que regula los mecanismos de participación mandatados por ley (92\%), son muy escasas las que generan en dicha normativa mecanismos propios de participación (32\%), y mucho menos aún las que, efectivamente, las han implementado durante el último año (17\%). Sumado esto a la evidente brecha entre el promedio de cumplimiento de transparencia activa (71\%) y el de implementación de buenas prácticas en transparencia (38\%), se hace evidente que, aunque existen incentivos para el cumplimiento formal de las normas, existen muy pocos para la innovación y el desarrollo de iniciativas propias por parte de las municipalidades.

\section{Visiones por región}

Como en las versiones pasadas, quisimos observar también los datos según regiones, pensando que pudiera existir algún tipo de relación entre las diversas zonas del país y el nivel de desarrollo de la institucionalidad para el gobierno abierto. Al revisar los datos, al igual que en las anteriores versiones se observa que existe poca diferencia entre las regiones de Chile, aunque con tendencias claras en los casos extremos: por primera vez la Región Metropolitana deja e primer lugar -aunque para quedar en el segundo puesto-frente a las municipalidades de la Región de Coquimbo. Mientras, en el otro extremo, y por tercera vez, las municipalidades de la Región de Arica y Parinacota se encuentran, en promedio, en el último lugar entre las regiones (tabla 5 y gráfico 3).

\section{Tabla 5. IIGAM 2020 - Promedios por región}

\begin{tabular}{|c|c|}
\hline Región & Promedio IIGAM \\
\hline Coquimbo & 0,60 \\
\hline Metropolitana de Santiago & 0,59 \\
\hline Atacama & 0,58 \\
\hline Valparaíso & 0,58 \\
\hline Del Biobío & 0,57 \\
\hline De los Lagos & 0,57 \\
\hline Tarapacá & 0,57 \\
\hline Del Maule & 0,56 \\
\hline Del Libertador Gral. Bernardo O'Higgins & 0,55 \\
\hline Aisén, del Gral. Carlos Ibáñez del Campo & 0,54 \\
\hline De la Araucanía & 0,53 \\
\hline Magallanes y de la Antártica Chilena & 0,53 \\
\hline Antofagasta & 0,52 \\
\hline Nuble & 0,50 \\
\hline De los Ríos & 0,47 \\
\hline Arica y Parinacota & 0,42 \\
\hline
\end{tabular}

FUENTE: elaboración propia 


\section{Gráfico 4. IIGAM 2020 - Promedios por región}

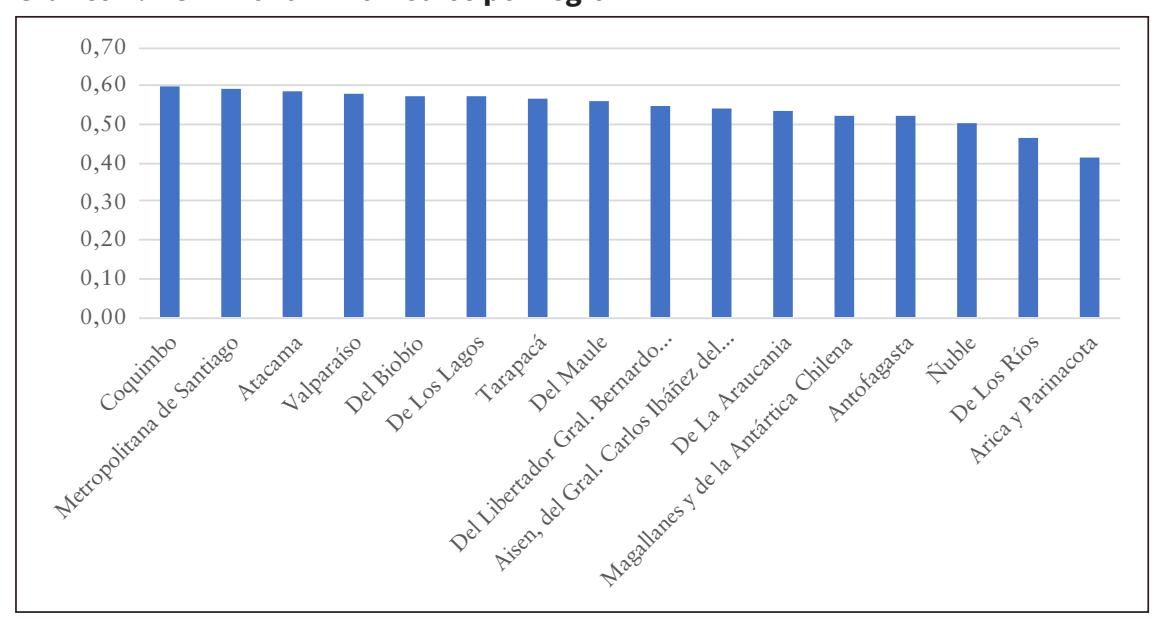

FUENTE: elaboración propia

\section{Visiones según niveles de desarrollo}

Por último, mostramos una revisión de los datos según la tipología de la Subsecretaría de Desarrollo Regional (Subdere), que divide las comunas en cinco tipos de comunas, siendo las del Tipo 1 las más urbanas, pobladas y con mayor desarrollo económico, mientras que el Tipo 5 reúne a las más rurales, con menor población y economías menos activas.

En términos generales, y tal como se observó en las versiones de 2016 y de 2018 , aunque existe una visible tendencia a que las municipalidades de comunas con mayor desarrollo tengan, a su vez, un mayor nivel de cumplimiento e implementación de mecanismos de gobierno abierto, dicha tendencia no se observa tan significativa (gráfico 4).

\section{Gráfico 5. IIGAM 2020 por tipología Subdere}

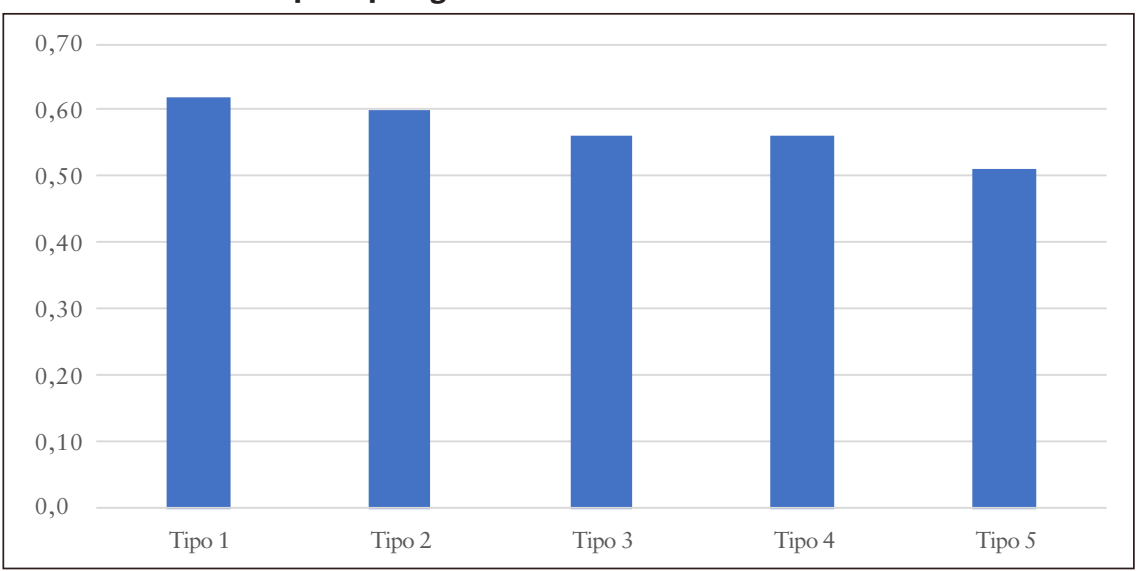

FUENTE: elaboración propia

Es más, como mencionamos anteriormente, en todos los tipos de comuna se observan casos interesantes, y en todos casos de rezago en cuanto a complimiento e implementación de mecanismos de gobierno abierto municipal. Por lo mismo, para observar con mayor atención tanto los avances como los desafíos observados, presentamos a continuación los datos municipales según la tipología Subdere. 


\section{-Tipo 1. Grandes comunas metropolitanas con alto y/o medio desarrollo}

Son 47 comunas las que hacen parte de esta tipología, pertenecientes en su gran mayoría a las zonas metropolitanas de Santiago, Concepción y Valparaíso, además de cuatro grandes capitales regionales. Entre ellas se encuentra el mayor puntaje a nivel nacional, la Municipalidad de La Cisterna, la cual repite entre los 20 primeros después de la medición de 2018.

Cuatro municipalidades de este grupo hacen parte de los primeros 10 puntajes a nivel nacional (La Cisterna, Peñalolén, Concepción y Pedro Aguirre Cerda). Entre las 10 primeras de esta categoría, solamente la ciudad de Concepción no hace parte de la Región Metropolitana. En el otro extremo, dos municipalidades de esta categoría hacen parte de los últimos 20 puestos a nivel nacional (La Reina e Independencia), con puntajes mínimos en su dimensión de Acceso a la Información.

Tabla 6. IIGAM 2020 - Resultados municipalidades Tipo 1 Subdere

\begin{tabular}{|c|c|c|c|c|c|c|c|}
\hline Municipalidad & Región & TA & AI & PB & PP & IIGAM 2020 & P. Nal. \\
\hline La Cisterna & Metropolitana de Santiago & 0,89 & 1,00 & 0,81 & 0,60 & 0,82 & 1 \\
\hline Peñalolén & Metropolitana de Santiago & 0,64 & 1,00 & 0,95 & 0,59 & 0,80 & 5 \\
\hline Concepción & Del Biobío & 0,62 & 1,00 & 0,85 & 0,69 & 0,79 & 6 \\
\hline Pedro Aguirre Cerda & Metropolitana de Santiago & 0,65 & 1,00 & 0,88 & 0,63 & 0,79 & 7 \\
\hline Lo Barnechea & Metropolitana de Santiago & 0,86 & 1,00 & 0,75 & 0,50 & 0,78 & 11 \\
\hline Huechuraba & Metropolitana de Santiago & 0,77 & 1,00 & 0,92 & 0,37 & 0,76 & 14 \\
\hline Lo Espejo & Metropolitana de Santiago & 0,73 & 1,00 & 0,75 & 0,57 & 0,76 & 15 \\
\hline Providencia & Metropolitana de Santiago & 0,91 & 0,83 & 0,70 & 0,52 & 0,74 & 27 \\
\hline Vitacura & Metropolitana de Santiago & 0,84 & 1,00 & 0,81 & 0,28 & 0,73 & 30 \\
\hline Talca & Del Maule & 0,60 & 1,00 & 0,90 & 0,41 & 0,73 & 32 \\
\hline Quilicura & Metropolitana de Santiago & 0,60 & 1,00 & 0,88 & 0,41 & 0,72 & 34 \\
\hline Chiguayante & Del Biobío & 0,69 & 1,00 & 0,83 & 0,34 & 0,72 & 37 \\
\hline Quinta Normal & Metropolitana de Santiago & 0,82 & 1,00 & 0,63 & 0,41 & 0,71 & 39 \\
\hline Valparaíso & Valparaíso & 0,48 & 1,00 & 0,80 & 0,53 & 0,70 & 44 \\
\hline San Bernardo & Metropolitana de Santiago & 0,62 & 0,83 & 0,90 & 0,39 & 0,69 & 62 \\
\hline Recoleta & Metropolitana de Santiago & 0,86 & 0,67 & 0,69 & 0,51 & 0,68 & 65 \\
\hline
\end{tabular}




\begin{tabular}{|c|c|c|c|c|c|c|c|}
\hline San Joaquín & Metropolitana de Santiago & 0,87 & 0,67 & 0,81 & 0,37 & 0,68 & 67 \\
\hline La Florida & Metropolitana de Santiago & 0,80 & 1,00 & 0,60 & 0,31 & 0,68 & 71 \\
\hline San Miguel & Metropolitana de Santiago & 0,63 & 1,00 & 0,69 & 0,38 & 0,68 & 72 \\
\hline La Granja & Metropolitana de Santiago & 0,73 & 0,67 & 0,69 & 0,53 & 0,65 & 88 \\
\hline Renca & Metropolitana de Santiago & 0,55 & 0,83 & 0,88 & 0,33 & 0,65 & 92 \\
\hline Santiago & Metropolitana de Santiago & 0,63 & 0,67 & 0,80 & 0,48 & 0,65 & 95 \\
\hline Las Condes & Metropolitana de Santiago & 0,60 & 0,83 & 0,75 & 0,39 & 0,64 & 98 \\
\hline Quilpué & Valparaíso & 0,47 & 1,00 & 0,69 & 0,41 & 0,64 & 99 \\
\hline Cerrillos & Metropolitana de Santiago & 0,51 & 0,83 & 0,67 & 0,52 & 0,63 & 110 \\
\hline Ñuñoa & Metropolitana de Santiago & 0,58 & 0,83 & 0,80 & 0,28 & 0,62 & 122 \\
\hline Rancagua & Del Libertador Gral. Bernardo O’Higgins & 0,68 & 0,83 & 0,60 & 0,34 & 0,62 & 126 \\
\hline San Pedro de la Paz & Del Biobío & 0,46 & 1,00 & 0,44 & 0,55 & 0,61 & 132 \\
\hline Lo Prado & Metropolitana de Santiago & 0,58 & 0,67 & 0,88 & 0,29 & 0,60 & 141 \\
\hline Macul & Metropolitana de Santiago & 0,46 & 0,67 & 0,94 & 0,31 & 0,59 & 153 \\
\hline Temuco & De la Araucanía & 0,68 & 1,00 & 0,00 & 0,64 & 0,58 & 163 \\
\hline Cerro Navia & Metropolitana de Santiago & 0,69 & 0,83 & 0,31 & 0,47 & 0,58 & 168 \\
\hline La Pintana & Metropolitana de Santiago & 0,49 & 0,67 & 0,75 & 0,39 & 0,57 & 173 \\
\hline Estación Central & Metropolitana de Santiago & 0,42 & 1,00 & 0,38 & 0,49 & 0,57 & 174 \\
\hline Hualpén & Del Biobío & 0,56 & 0,58 & 0,69 & 0,43 & 0,56 & 185 \\
\hline Maipú & Metropolitana de Santiago & 0,62 & 1,00 & 0,00 & 0,61 & 0,56 & 194 \\
\hline Puente Alto & Metropolitana de Santiago & 0,47 & 0,67 & 0,75 & 0,30 & 0,55 & 200 \\
\hline Viña del Mar & Valparaíso & 0,38 & 1,00 & 0,20 & 0,45 & 0,51 & 221 \\
\hline Talcahuano & Del Biobío & 0,65 & 0,67 & 0,25 & 0,45 & 0,51 & 222 \\
\hline Pudahuel & Metropolitana de Santiago & 0,61 & 0,83 & 0,20 & 0,37 & 0,51 & 223 \\
\hline San Ramón & Metropolitana de Santiago & 0,42 & 0,83 & 0,38 & 0,37 & 0,50 & 227 \\
\hline Conchalí & Metropolitana de Santiago & 0,81 & 0,00 & 0,81 & 0,31 & 0,48 & 239 \\
\hline Antofagasta & Antofagasta & 0,62 & 0,83 & 0,05 & 0,32 & 0,46 & 259 \\
\hline El Bosque & Metropolitana de Santiago & 0,48 & 0,67 & 0,13 & 0,47 & 0,44 & 275 \\
\hline Villa Alemana & Valparaíso & 0,61 & 0,67 & 0,00 & 0,29 & 0,39 & 309 \\
\hline La Reina & Metropolitana de Santiago & 0,60 & 0,00 & 0,38 & 0,26 & 0,31 & 330 \\
\hline Independencia & Metropolitana de Santiago & 0,29 & 0,00 & 0,31 & 0,33 & 0,23 & 342 \\
\hline
\end{tabular}

FUENTE: elaboración propia 


\section{- Tipo 2. Comunas mayores, con desarrollo medio}

Son 37 comunas las que conforman esta tipología, incluyendo la mayoría de las capitales regionales del país. Lidera este grupo, precisamente, la capital de la Región de Coquimbo, La Serena, ubicándose en el puesto 9 a nivel nacional, seguida por las comunas de Lota, en la Región del Biobío, y San Antonio, en la Región de Valparaíso. Al final de la tabla se encuentran, a su vez, dos capitales regionales: la ciudad de Chillán, de la nueva Región de Ñuble, y la ciudad de Valdivia, de la Región de los Ríos, siendo esta última la única de esta categoría en entrar dentro de los últimos 20 puestos a nivel nacional.

\section{Tabla 7. IIGAM 2020 - Resultados municipalidades Tipo 2 Subdere}

\begin{tabular}{|c|c|c|c|c|c|c|c|}
\hline Municipalidad & Región & TA & Al & PB & PP & IIGAM 2020 & P. Nal \\
\hline La Serena & Coquimbo & 0,77 & 1,00 & 0,75 & 0,61 & 0,78 & 9 \\
\hline Lota & Del Biobío & 0,61 & 1,00 & 1,00 & 0,36 & 0,74 & 28 \\
\hline San Antonio & Valparaíso & 0,62 & 0,75 & 0,94 & 0,62 & 0,73 & 31 \\
\hline Coronel & Del Biobío & 0,53 & 1,00 & 0,88 & 0,45 & 0,71 & 40 \\
\hline Pirque & Metropolitana de Santiago & 0,54 & 1,00 & 0,83 & 0,45 & 0,71 & 42 \\
\hline Copiapó & Atacama & 0,66 & 0,67 & 0,81 & 0,63 & 0,69 & 56 \\
\hline Iquique & Tarapacá & 0,37 & 0,83 & 0,90 & 0,65 & 0,69 & 59 \\
\hline Los Ángeles & Del Biobío & 0,60 & 1,00 & 0,70 & 0,41 & 0,68 & 70 \\
\hline Colina & Metropolitana de Santiago & 0,74 & 0,67 & 0,94 & 0,35 & 0,68 & 73 \\
\hline Cartagena & Valparaíso & 0,62 & 0,75 & 0,50 & 0,81 & 0,67 & 75 \\
\hline Quillota & Valparaíso & 0,57 & 0,67 & 1,00 & 0,44 & 0,67 & 76 \\
\hline Arica & Arica y Parinacota & 0,59 & 0,67 & 1,00 & 0,40 & 0,66 & 78 \\
\hline Alto Hospicio & Tarapacá & 0,63 & 0,67 & 0,92 & 0,44 & 0,66 & 79 \\
\hline Puerto Varas & De los Lagos & 0,74 & 0,67 & 0,75 & 0,45 & 0,65 & 90 \\
\hline Curicó & Del Maule & 0,30 & 1,00 & 0,81 & 0,47 & 0,65 & 94 \\
\hline Coquimbo & Coquimbo & 0,62 & 0,67 & 1,00 & 0,26 & 0,64 & 105 \\
\hline Penco & Del Biobío & 0,48 & 0,67 & 0,92 & 0,48 & 0,64 & 106 \\
\hline La Calera & Valparaíso & 0,52 & 0,75 & 0,83 & 0,42 & 0,63 & 112 \\
\hline Santo Domingo & Valparaíso & 0,35 & 0,83 & 0,92 & 0,42 & 0,63 & 115 \\
\hline Calama & Antofagasta & 0,58 & 0,67 & 0,88 & 0,35 & 0,62 & 125 \\
\hline
\end{tabular}




\begin{tabular}{|c|c|c|c|c|c|c|c|}
\hline Talagante & Metropolitana de Santiago & 0,72 & 0,67 & 0,75 & 0,32 & 0,61 & 128 \\
\hline Puerto Montt & De los Lagos & 0,55 & 0,83 & 0,75 & 0,27 & 0,60 & 140 \\
\hline La Cruz & Valparaíso & 0,31 & 0,83 & 0,92 & 0,34 & 0,60 & 143 \\
\hline Tomé & Del Biobío & 0,79 & 0,67 & 0,58 & 0,35 & 0,60 & 147 \\
\hline Punta Arenas & Magallanes y de la Antártica Chilena & 0,88 & 0,67 & 0,56 & 0,26 & 0,59 & 152 \\
\hline Lampa & Metropolitana de Santiago & 0,43 & 0,67 & 0,75 & 0,35 & 0,55 & 199 \\
\hline Concón & Valparaíso & 0,57 & 0,67 & 0,67 & 0,29 & 0,55 & 201 \\
\hline Osorno & De los Lagos & 0,76 & 0,67 & 0,25 & 0,46 & 0,53 & 207 \\
\hline Machalí & Del Libertador Gral. Bernardo O’Higgins & 0,66 & 0,75 & 0,25 & 0,42 & 0,52 & 212 \\
\hline EL Tabo & Valparaíso & 0,53 & 1,00 & 0,17 & 0,24 & 0,48 & 235 \\
\hline Chillán Viejo & Ñuble & 0,56 & 0,67 & 0,25 & 0,44 & 0,48 & 243 \\
\hline Buin & Metropolitana de Santiago & 0,53 & 0,00 & 1,00 & 0,30 & 0,46 & 257 \\
\hline Coyhaique & Aisén, del Gral. Carlos Ibáñez del Campo & 0,66 & 0,00 & 0,83 & 0,32 & 0,45 & 259 \\
\hline Padre Hurtado & Metropolitana de Santiago & 0,61 & 0,67 & 0,25 & 0,24 & 0,44 & 270 \\
\hline Peñaflor & Metropolitana de Santiago & 0,47 & 0,75 & 0,17 & 0,37 & 0,44 & 272 \\
\hline Chillán & Ñuble & 0,49 & 0,42 & 0,44 & 0,34 & 0,42 & 291 \\
\hline Valdivia & De los Ríos & 0,68 & 0,00 & 0,13 & 0,31 & 0,28 & 334 \\
\hline
\end{tabular}

FUENTE: elaboración propia

De los Ríos

0,13 


\section{- Tipo 3. Comunas urbanas medianas, con desarrollo medio}

Esta tipología reúne pequeñas ciudades de todo Chile, en ocasiones cabeceras municipales de zonas rurales del país. Entre ellas, tres alcanzan a estar entre los mejores 20 puntajes a nivel nacional: Traiguén, en La Araucanía, Molina en Maule y Caldera en Atacama, seguidas muy de cerca por El Quisco, en Valparaíso, Curacautín en La Araucanía y Nacimiento en el Biobío. Al final de la tabla encontramos, en cambio, cinco municipalidades de esta tipología pertenecientes a los últimos 20 puntajes a nivel nacional: Quirihue, en el Ñuble, Río Bueno en Los Ríos, Renaico en La Araucanía, Mostazal en O'Higgins y San Carlos, también en Ñuble.

\section{Tabla 8. IIGAM 2020 - Resultados municipalidades Tipo 3 Subdere}

\begin{tabular}{|c|c|c|c|c|c|c|c|}
\hline Municipalidad & Región & TA & Al & PB & PP & IIGAM 2020 & P. Nal. \\
\hline Traiguén & De la Araucanía & 0,63 & 1,00 & 1,00 & 0,50 & 0,78 & 10 \\
\hline Molina & Del Maule & 0,83 & 1,00 & 0,83 & 0,36 & 0,76 & 17 \\
\hline Caldera & Atacama & 0,43 & 1,00 & 1,00 & 0,58 & 0,75 & 19 \\
\hline El Quisco & Valparaíso & 0,64 & 1,00 & 0,92 & 0,44 & 0,75 & 21 \\
\hline Curacautín & De la Araucanía & 0,83 & 1,00 & 0,83 & 0,32 & 0,75 & 25 \\
\hline Nacimiento & Del Biobío & 0,69 & 1,00 & 0,75 & 0,54 & 0,74 & 26 \\
\hline Parral & Del Maule & 0,61 & 1,00 & 0,83 & 0,43 & 0,72 & 36 \\
\hline San Javier & Del Maule & 0,58 & 0,83 & 0,92 & 0,46 & 0,70 & 48 \\
\hline Padre Las Casas & De la Araucanía & 0,75 & 1,00 & 0,67 & 0,36 & 0,69 & 55 \\
\hline Hijuelas & Valparaíso & 0,39 & 1,00 & 1,00 & 0,38 & 0,69 & 57 \\
\hline Cauquenes & Del Maule & 0,58 & 1,00 & 0,67 & 0,50 & 0,69 & 61 \\
\hline San Rosendo & Del Biobío & 0,63 & 0,75 & 0,83 & 0,52 & 0,68 & 64 \\
\hline Tocopilla & Antofagasta & 0,66 & 0,83 & 0,83 & 0,37 & 0,67 & 74 \\
\hline Linares & Del Maule & 0,51 & 1,00 & 0,75 & 0,39 & 0,66 & 83 \\
\hline Collipulli & De la Araucanía & 0,59 & 0,67 & 0,92 & 0,45 & 0,66 & 86 \\
\hline Chañaral & Atacama & 0,47 & 0,67 & 1,00 & 0,47 & 0,65 & 89 \\
\hline Ancud & De los Lagos & 0,57 & 0,83 & 0,83 & 0,34 & 0,65 & 96 \\
\hline Vallenar & Atacama & 0,43 & 0,75 & 1,00 & 0,39 & 0,64 & 97 \\
\hline San Felipe & Valparaíso & 0,75 & 0,67 & 0,75 & 0,40 & 0,64 & 101 \\
\hline
\end{tabular}




\begin{tabular}{|c|c|c|c|c|c|c|c|}
\hline Loncoche & De la Araucanía & 0,28 & 1,00 & 1,00 & 0,28 & 0,64 & 104 \\
\hline Ovalle & Coquimbo & 0,69 & 0,42 & 0,94 & 0,50 & 0,64 & 108 \\
\hline Castro & De los Lagos & 0,85 & 1,00 & 0,17 & 0,51 & 0,63 & 113 \\
\hline Villarrica & De la Araucanía & 0,73 & 1,00 & 0,33 & 0,44 & 0,63 & 117 \\
\hline Gorbea & De la Araucanía & 0,74 & 0,67 & 0,75 & 0,34 & 0,62 & 118 \\
\hline Taltal & Antofagasta & 0,66 & 0,67 & 0,75 & 0,37 & 0,61 & 131 \\
\hline Limache & Valparaíso & 0,52 & 0,67 & 0,92 & 0,32 & 0,61 & 137 \\
\hline Pitrufquén & De la Araucanía & 0,44 & 0,75 & 0,83 & 0,36 & 0,60 & 150 \\
\hline Mulchén & Del Biobío & 0,47 & 0,83 & 0,67 & 0,38 & 0,59 & 158 \\
\hline Andacollo & Coquimbo & 0,34 & 0,67 & 1,00 & 0,35 & 0,59 & 161 \\
\hline Angol & De la Araucanía & 0,42 & 0,67 & 0,92 & 0,31 & 0,58 & 167 \\
\hline Quintero & Valparaíso & 0,40 & 0,67 & 0,83 & 0,41 & 0,58 & 169 \\
\hline Constitución & Del Maule & 0,35 & 0,67 & 0,92 & 0,33 & 0,57 & 183 \\
\hline Lanco & De los Ríos & 0,65 & 0,83 & 0,33 & 0,44 & 0,56 & 188 \\
\hline Pichilemu & Del Libertador Gral. Bernardo O’Higgins & 0,54 & 1,00 & 0,42 & 0,29 & 0,56 & 190 \\
\hline Cabrero & Del Biobío & 0,49 & 0,83 & 0,33 & 0,57 & 0,56 & 193 \\
\hline Los Álamos & Del Biobío & 0,22 & 0,67 & 0,92 & 0,35 & 0,54 & 206 \\
\hline Graneros & Del Libertador Gral. Bernardo O’Higgins & 0,37 & 1,00 & 0,33 & 0,33 & 0,51 & 220 \\
\hline Los Andes & Valparaíso & 0,59 & 0,67 & 0,67 & 0,05 & 0,49 & 227 \\
\hline Olmué & Valparaíso & 0,32 & 0,67 & 0,67 & 0,26 & 0,48 & 242 \\
\hline Curanilahue & Del Biobío & 0,28 & 0,67 & 0,50 & 0,44 & 0,47 & 249 \\
\hline Illapel & Coquimbo & 0,47 & 0,42 & 0,58 & 0,41 & 0,47 & 250 \\
\hline Santa Bárbara & Del Biobío & 0,57 & 0,67 & 0,25 & 0,38 & 0,47 & 253 \\
\hline Doñihue & Del Libertador Gral. Bernardo O’Higgins & 0,75 & 0,67 & 0,08 & 0,32 & 0,45 & 260 \\
\hline Lautaro & De la Araucanía & 0,68 & 0,67 & 0,08 & 0,32 & 0,44 & 273 \\
\hline Lebu & Del Biobío & 0,72 & 0,00 & 0,75 & 0,27 & 0,44 & 275 \\
\hline Puerto Natales & Magallanes y de la Antártica Chilena & 0,67 & 0,75 & 0,00 & 0,31 & 0,43 & 281 \\
\hline El Monte & Metropolitana de Santiago & 0,51 & 0,67 & 0,00 & 0,53 & 0,43 & 286 \\
\hline Victoria & De la Araucanía & 0,43 & 0,67 & 0,08 & 0,45 & 0,41 & 298 \\
\hline Yungay & Ñuble & 0,51 & 0,00 & 0,75 & 0,37 & 0,41 & 301 \\
\hline Rinconada & Valparaíso & 0,45 & 0,00 & 1,00 & 0,13 & 0,40 & 304 \\
\hline Cañete & Del Biobío & 0,33 & 0,67 & 0,08 & 0,37 & 0,36 & 318 \\
\hline
\end{tabular}




\begin{tabular}{|c|c|c|c|c|c|c|c|}
\hline Quirihue & Ñuble & 0,35 & 0,42 & 0,33 & 0,25 & 0,34 & 325 \\
\hline Río Bueno & De los Ríos & 0,46 & 0,00 & 0,50 & 0,34 & 0,33 & 326 \\
\hline Renaico & De la Araucanía & 0,38 & 0,67 & 0,00 & 0,25 & 0,32 & 327 \\
\hline Mostazal & Del Libertador Gral. Bernardo O'Higgins & 0,67 & 0,00 & 0,25 & 0,27 & 0,30 & 332 \\
\hline San Carlos & Ñuble & 0,40 & 0,00 & 0,25 & 0,40 & 0,26 & 338 \\
\hline
\end{tabular}

FUENTE: elaboración propia 


\section{- Tipo 4. Comunas semiurbanas y rurales, con desarrollo medio}

Son 96 las comunas que conforman este tipo, penúltimo en nivel de desarrollo. Aun así, observamos que siete de ellas alcanzan niveles de cumplimiento e implementación dentro del primer cuartil, al lado de grandes municipalidades, con significativas diferencias en ingresos y capacidades. Este es el caso de las comunas de Laja, en el Biobío; Purranque, en Los Lagos, y Cochrane, en Aisén (las cuales, además, se encuentran entre las 10 primeras del país), seguidas por Pucón, en La Araucanía; Fresia, en Los Lagos; Calle Larga, en Valparaíso, y Chile Chico, en Aisén.

Al mismo tiempo, solamente dos municipalidades de esta categoría entran en los últimos 20 puntajes del país: Primavera, en Magallanes, y Futrono, en la Región de Los Lagos. En promedio, las municipalidades de esta categoría alcanzan el mismo nivel que las de la categoría $3(0,56)$.

Tabla 9. IIGAM 2020 - Resultados municipalidades Tipo 4 Subdere

\begin{tabular}{|c|c|c|c|c|c|c|c|}
\hline Municipalidad & Región & TA & Al & PB & PP & IIGAM 2020 & P. Nal. \\
\hline Laja & Del Biobío & 0,84 & 1,00 & 0,75 & 0,60 & 0,80 & 3 \\
\hline Purranque & De los Lagos & 0,73 & 1,00 & 1,00 & 0,46 & 0,80 & 4 \\
\hline Cochrane & Aisén, del Gral. Carlos Ibáñez del Campo & 0,79 & 1,00 & 0,83 & 0,53 & 0,79 & 8 \\
\hline Pucón & De la Araucanía & 0,70 & 1,00 & 1,00 & 0,37 & 0,77 & 13 \\
\hline Fresia & De los Lagos & 0,55 & 1,00 & 0,92 & 0,55 & 0,75 & 18 \\
\hline Calle Larga & Valparaíso & 0,67 & 0,83 & 0,92 & 0,57 & 0,75 & 22 \\
\hline Chile Chico & Aisén, del Gral. Carlos Ibáñez del Campo & 0,65 & 1,00 & 0,92 & 0,42 & 0,75 & 23 \\
\hline Ránquil & Ñuble & 0,67 & 1,00 & 0,83 & 0,39 & 0,72 & 33 \\
\hline Cabildo & Valparaíso & 0,83 & 1,00 & 0,50 & 0,54 & 0,72 & 35 \\
\hline Pozo Almonte & Tarapacá & 0,80 & 0,83 & 0,92 & 0,31 & 0,72 & 38 \\
\hline Río Negro & De los Lagos & 0,79 & 0,67 & 1,00 & 0,37 & 0,71 & 41 \\
\hline Zapallar & Valparaíso & 0,62 & 1,00 & 0,83 & 0,37 & 0,70 & 43 \\
\hline Maullín & De los Lagos & 0,53 & 1,00 & 1,00 & 0,27 & 0,70 & 45 \\
\hline Río lbáñez & Aisén, del Gral. Carlos Ibáñez del Campo & 0,59 & 1,00 & 0,75 & 0,46 & 0,70 & 47 \\
\hline Coinco & Del Libertador Gral. Bernardo O’Higgins & 0,62 & 1,00 & 1,00 & 0,17 & 0,70 & 49 \\
\hline San Pablo & De los Lagos & 0,62 & 0,75 & 0,92 & 0,49 & 0,69 & 53 \\
\hline
\end{tabular}




\begin{tabular}{|c|c|c|c|c|c|c|c|}
\hline Hualaihué & De los Lagos & 0,61 & 0,75 & 1,00 & 0,40 & 0,69 & 58 \\
\hline Cisnes & Aisén, del Gral. Carlos Ibáñez del Campo & 0,72 & 0,67 & 1,00 & 0,36 & 0,69 & 60 \\
\hline Quinchao & De los Lagos & 0,53 & 1,00 & 0,92 & 0,27 & 0,68 & 69 \\
\hline Paillaco & De los Ríos & 0,59 & 0,83 & 0,75 & 0,48 & 0,66 & 80 \\
\hline Curacaví & Metropolitana de Santiago & 0,74 & 0,67 & 0,92 & 0,33 & 0,66 & 81 \\
\hline Palmilla & Del Libertador Gral. Bernardo O'Higgins & 0,68 & 1,00 & 0,67 & 0,30 & 0,66 & 84 \\
\hline Cochamó & De los Lagos & 0,76 & 0,67 & 0,83 & 0,36 & 0,65 & 87 \\
\hline Mariquina & De los Ríos & 0,71 & 1,00 & 0,50 & 0,35 & 0,64 & 102 \\
\hline Dalcahue & De los Lagos & 0,81 & 0,67 & 0,75 & 0,32 & 0,64 & 107 \\
\hline Huasco & Atacama & 0,43 & 0,75 & 0,83 & 0,53 & 0,64 & 109 \\
\hline Cabo de Hornos & Magallanes y de la Antártica Chilena & 0,71 & 0,67 & 0,75 & 0,41 & 0,63 & 111 \\
\hline Coltauco & Del Libertador Gral. Bernardo O'Higgins & 0,70 & 0,42 & 1,00 & 0,39 & 0,63 & 116 \\
\hline Panquehue & Valparaíso & 0,64 & 0,83 & 0,75 & 0,27 & 0,62 & 120 \\
\hline Romeral & Del Maule & 0,58 & 0,67 & 1,00 & 0,24 & 0,62 & 123 \\
\hline San Esteban & Valparaíso & 0,51 & 0,83 & 0,83 & 0,28 & 0,61 & 129 \\
\hline Nancagua & Del Libertador Gral. Bernardo O'Higgins & 0,47 & 0,83 & 0,67 & 0,48 & 0,61 & 130 \\
\hline Casablanca & Valparaíso & 0,58 & 1,00 & 0,50 & 0,35 & 0,61 & 133 \\
\hline Catemu & Valparaíso & 0,49 & 0,67 & 0,83 & 0,44 & 0,61 & 134 \\
\hline Alhué & Metropolitana de Santiago & 0,50 & 1,00 & 0,50 & 0,43 & 0,61 & 136 \\
\hline Requínoa & Del Libertador Gral. Bernardo O’Higgins & 0,75 & 1,00 & 0,17 & 0,50 & 0,61 & 138 \\
\hline Chaitén & De los Lagos & 0,64 & 0,67 & 0,75 & 0,36 & 0,61 & 139 \\
\hline San Gregorio & Magallanes y de la Antártica Chilena & 0,49 & 0,67 & 0,92 & 0,33 & 0,60 & 142 \\
\hline Olivar & Del Libertador Gral. Bernardo O’Higgins & 0,63 & 0,67 & 0,83 & 0,26 & 0,60 & 146 \\
\hline Chimbarongo & Del Libertador Gral. Bernardo O’Higgins & 0,66 & 0,67 & 0,75 & 0,31 & 0,60 & 149 \\
\hline Tierra Amarilla & Atacama & 0,39 & 0,67 & 0,92 & 0,40 & 0,59 & 151 \\
\hline Nogales & Valparaíso & 0,63 & 0,67 & 0,83 & 0,25 & 0,59 & 154 \\
\hline Quinta de Tilcoco & Del Libertador Gral. Bernardo O'Higgins & 0,30 & 0,83 & 0,92 & 0,31 & 0,59 & 157 \\
\hline Arauco & Del Biobío & 0,70 & 1,00 & 0,08 & 0,57 & 0,59 & 159 \\
\hline San Fernando & Del Libertador Gral. Bernardo O’Higgins & 0,39 & 1,00 & 0,67 & 0,30 & 0,59 & 160 \\
\hline Calbuco & De los Lagos & 0,73 & 1,00 & 0,25 & 0,34 & 0,58 & 166 \\
\hline Los Vilos & Coquimbo & 0,66 & 1,00 & 0,08 & 0,55 & 0,57 & 170 \\
\hline Llanquihue & De los Lagos & 0,37 & 0,67 & 1,00 & 0,25 & 0,57 & 175 \\
\hline
\end{tabular}




\begin{tabular}{|c|c|c|c|c|c|c|c|}
\hline La Estrella & Del Libertador Gral. Bernardo O’Higgins & 0,51 & 0,58 & 0,83 & 0,36 & 0,57 & 177 \\
\hline Santa María & Valparaíso & 0,54 & 1,00 & 0,17 & 0,57 & 0,57 & 178 \\
\hline Rengo & Del Libertador Gral. Bernardo O’Higgins & 0,55 & 0,58 & 0,75 & 0,39 & 0,57 & 179 \\
\hline Puyehue & De los Lagos & 0,70 & 0,67 & 0,50 & 0,39 & 0,56 & 187 \\
\hline Santa Cruz & Del Libertador Gral. Bernardo O'Higgins & 0,54 & 0,67 & 0,83 & 0,20 & 0,56 & 192 \\
\hline San Vicente de Tagua Tagua & Del Libertador Gral. Bernardo O’Higgins & 0,75 & 0,67 & 0,42 & 0,39 & 0,56 & 195 \\
\hline Papudo & Valparaíso & 0,47 & 0,67 & 0,83 & 0,23 & 0,55 & 198 \\
\hline Bulnes & Ñuble & 0,59 & 1,00 & 0,08 & 0,52 & 0,55 & 202 \\
\hline San José de Maipo & Metropolitana de Santiago & 0,43 & 0,67 & 0,75 & 0,31 & 0,54 & 204 \\
\hline La Ligua & Valparaíso & 0,28 & 0,67 & 0,83 & 0,35 & 0,53 & 208 \\
\hline María Elena & Antofagasta & 0,36 & 1,00 & 0,50 & 0,25 & 0,53 & 210 \\
\hline Teno & Del Maule & 0,60 & 1,00 & 0,08 & 0,42 & 0,53 & 211 \\
\hline Vichuquén & Del Maule & 0,44 & 0,58 & 0,75 & 0,30 & 0,52 & 214 \\
\hline Cunco & De la Araucanía & 0,56 & 0,75 & 0,42 & 0,33 & 0,51 & 216 \\
\hline Paihuano & Coquimbo & 0,29 & 0,67 & 0,83 & 0,25 & 0,51 & 218 \\
\hline Llaillay & Valparaíso & 0,19 & 0,67 & 0,92 & 0,26 & 0,51 & 219 \\
\hline Algarrobo & Valparaíso & 0,35 & 0,67 & 0,75 & 0,24 & 0,50 & 223 \\
\hline Paine & Metropolitana de Santiago & 0,53 & 1,00 & 0,25 & 0,23 & 0,50 & 224 \\
\hline Tiltil & Metropolitana de Santiago & 0,59 & 0,00 & 1,00 & 0,35 & 0,49 & 233 \\
\hline Peumo & Del Libertador Gral. Bernardo O’Higgins & 0,57 & 1,00 & 0,00 & 0,37 & 0,49 & 234 \\
\hline La Unión & De los Ríos & 0,74 & 0,67 & 0,17 & 0,36 & 0,48 & 236 \\
\hline Porvenir & Magallanes y de la Antártica Chilena & 0,47 & 0,42 & 0,75 & 0,29 & 0,48 & 240 \\
\hline Melipilla & Metropolitana de Santiago & 0,72 & 0,00 & 0,81 & 0,39 & 0,48 & 241 \\
\hline Codegua & Del Libertador Gral. Bernardo O'Higgins & 0,61 & 0,67 & 0,17 & 0,46 & 0,48 & 244 \\
\hline Pica & Tarapacá & 0,64 & 0,83 & 0,08 & 0,33 & 0,47 & 248 \\
\hline Puerto Aisén & Aisén, del Gral. Carlos Ibáñez del Campo & 0,45 & 0,67 & 0,42 & 0,31 & 0,46 & 254 \\
\hline Diego de Almagro & Atacama & 0,47 & 0,67 & 0,50 & 0,21 & 0,46 & 255 \\
\hline Mejillones & Antofagasta & 0,78 & 0,42 & 0,33 & 0,31 & 0,46 & 256 \\
\hline Vilcún & De la Araucanía & 0,56 & 0,58 & 0,25 & 0,42 & 0,45 & 261 \\
\hline Puchuncavi & Valparaíso & 0,44 & 0,83 & 0,17 & 0,37 & 0,45 & 262 \\
\hline Las Cabras & Del Libertador Gral. Bernardo O'Higgins & 0,75 & 0,67 & 0,08 & 0,30 & 0,45 & 263 \\
\hline Vicuña & Coquimbo & 0,47 & 0,00 & 0,83 & 0,48 & 0,45 & 264 \\
\hline
\end{tabular}




\begin{tabular}{|c|c|c|c|c|c|c|c|}
\hline Los Muermos & De los Lagos & 0,68 & 0,42 & 0,33 & 0,36 & 0,45 & 265 \\
\hline Sierra Gorda & Antofagasta & 0,58 & 1,00 & 0,08 & 0,09 & 0,44 & 271 \\
\hline Chonchi & De los Lagos & 0,68 & 0,67 & 0,00 & 0,38 & 0,43 & 282 \\
\hline Freirina & Atacama & 0,27 & 0,75 & 0,25 & 0,41 & 0,42 & 290 \\
\hline Isla de Maipo & Metropolitana de Santiago & 0,53 & 0,67 & 0,08 & 0,35 & 0,41 & 297 \\
\hline San Pedro de Atacama & Antofagasta & 0,26 & 0,42 & 0,67 & 0,28 & 0,41 & 299 \\
\hline Calera de Tango & Metropolitana de Santiago & 0,54 & 0,42 & 0,33 & 0,33 & 0,40 & 302 \\
\hline Palena & De los Lagos & 0,59 & 0,67 & 0,00 & 0,36 & 0,40 & 303 \\
\hline Los Lagos & De los Ríos & 0,61 & 0,00 & 0,58 & 0,39 & 0,40 & 306 \\
\hline Máfil & De los Ríos & 0,56 & 0,67 & 0,00 & 0,34 & 0,39 & 307 \\
\hline Frutillar & De los Lagos & 0,47 & 0,67 & 0,00 & 0,40 & 0,39 & 310 \\
\hline Quellón & De los Lagos & 0,43 & 0,67 & 0,17 & 0,28 & 0,39 & 311 \\
\hline Futaleufú & De los Lagos & 0,44 & 0,67 & 0,17 & 0,24 & 0,38 & 314 \\
\hline Puerto Octay & De los Lagos & 0,38 & 0,83 & 0,00 & 0,26 & 0,37 & 317 \\
\hline Primavera & Magallanes y de la Antártica Chilena & 0,53 & 0,42 & 0,00 & 0,31 & 0,31 & 328 \\
\hline Futrono & De los Ríos & 0,27 & 0,75 & 0,08 & 0,10 & 0,30 & 330 \\
\hline
\end{tabular}

FUENTE: elaboración propia 


\section{- Tipo 5. Comunas semiurbanas y rurales de bajo desarrollo}

Esta última categoría recoge las comunas con bajo nivel de desarrollo en el país. Es la categoría más numerosa, pues incluye 109 municipalidades de todo Chile. Sin embargo, encontramos en esta categoría casos muy interesantes, como Santa Juana, en la Región del Biobío, la cual, a pesar de contar con niveles bajos de desarrollo, ha logrado alcanzar el segundo puntaje a nivel nacional, en gran parte por la rigurosidad de sus respuestas y la excelente gestión de la información en cuanto a la implementación de sus mecanismos participativos. Le siguen, dentro de los primeros 20 puntajes nacionales, las municipalidades de Navidad, en O'Higgins; Tucapel, en el Biobío, y San Nicolás, en Ñuble.

Sin embargo, también es la categoría que más comunas tiene en los últimos lugares nacionales, donde 10 de los últimos 20 lugares hacen parte de esta tipología, incluyendo los últimos tres puestos de esta medición: O’Higgins, en la Región de Aisén; Toltén, en la Región de la Araucanía, y Camarones, en la Región de Arica y Parinacota.

\section{Tabla 10. IIGAM 2020 - Resultados municipalidades Tipo 5 Subdere}

\begin{tabular}{|c|c|c|c|c|c|c|c|}
\hline Municipalidad & Región & TA & Al & PB & PP & IIGAM 2020 & P. Nal. \\
\hline Santa Juana & Del Biobío & 0,50 & 1,00 & 1,00 & 0,77 & 0,82 & 2 \\
\hline Navidad & Del Libertador Gral. Bernardo O’Higgins & 0,63 & 0,83 & 1,00 & 0,63 & 0,77 & 12 \\
\hline Tucapel & Del Biobío & 0,46 & 1,00 & 1,00 & 0,57 & 0,76 & 16 \\
\hline San Nicolás & Ñuble & 0,45 & 1,00 & 1,00 & 0,55 & 0,75 & 20 \\
\hline Monte Patria & Coquimbo & 0,59 & 1,00 & 0,83 & 0,56 & 0,75 & 24 \\
\hline Cobquecura & Ñuble & 0,71 & 1,00 & 0,92 & 0,33 & 0,74 & 29 \\
\hline Lago Ranco & De los Ríos & 0,58 & 0,83 & 0,83 & 0,55 & 0,70 & 46 \\
\hline San Clemente & Del Maule & 0,61 & 0,83 & 0,83 & 0,50 & 0,70 & 50 \\
\hline Putaendo & Valparaíso & 0,62 & 1,00 & 0,92 & 0,24 & 0,69 & 51 \\
\hline Nueva Imperial & De la Araucanía & 0,31 & 1,00 & 0,92 & 0,55 & 0,69 & 52 \\
\hline Los Sauces & De la Araucanía & 0,56 & 0,83 & 1,00 & 0,38 & 0,69 & 54 \\
\hline Hualañé & Del Maule & 0,63 & 1,00 & 0,83 & 0,27 & 0,68 & 63 \\
\hline Punitaqui & Coquimbo & 0,36 & 1,00 & 1,00 & 0,36 & 0,68 & 66 \\
\hline Licantén & Del Maule & 0,54 & 1,00 & 0,83 & 0,34 & 0,68 & 68 \\
\hline
\end{tabular}




\begin{tabular}{|c|c|c|c|c|c|c|c|}
\hline Río Hurtado & Coquimbo & 0,34 & 1,00 & 1,00 & 0,32 & 0,67 & 77 \\
\hline El Carmen & Ñuble & 0,61 & 0,83 & 0,83 & 0,37 & 0,66 & 82 \\
\hline Quemchi & De los Lagos & 0,63 & 0,83 & 0,83 & 0,32 & 0,66 & 85 \\
\hline Salamanca & Coquimbo & 0,63 & 1,00 & 0,33 & 0,63 & 0,65 & 91 \\
\hline Litueche & Del Libertador Gral. Bernardo O’Higgins & 0,57 & 0,75 & 0,83 & 0,44 & 0,65 & 93 \\
\hline Río Claro & Del Maule & 0,59 & 0,67 & 1,00 & 0,32 & 0,64 & 100 \\
\hline Cholchol & De la Araucanía & 0,42 & 1,00 & 0,83 & 0,31 & 0,64 & 103 \\
\hline Ercilla & De la Araucanía & 0,41 & 1,00 & 0,83 & 0,28 & 0,63 & 114 \\
\hline Portezuelo & Ñuble & 0,78 & 0,67 & 0,67 & 0,38 & 0,62 & 119 \\
\hline Camiña & Tarapacá & 0,53 & 0,75 & 0,83 & 0,37 & 0,62 & 121 \\
\hline San Fabián & Ñuble & 0,70 & 0,67 & 0,67 & 0,46 & 0,62 & 124 \\
\hline Panguipulli & De los Ríos & 0,66 & 0,83 & 0,67 & 0,29 & 0,61 & 127 \\
\hline Puqueldón & De los Lagos & 0,45 & 1,00 & 0,67 & 0,31 & 0,61 & 135 \\
\hline Peralillo & Del Libertador Gral. Bernardo O'Higgins & 0,56 & 0,67 & 0,83 & 0,34 & 0,60 & 144 \\
\hline Freire & De la Araucanía & 0,57 & 0,67 & 0,83 & 0,32 & 0,60 & 145 \\
\hline Chanco & Del Maule & 0,39 & 1,00 & 0,92 & 0,09 & 0,60 & 148 \\
\hline Pumanque & Del Libertador Gral. Bernardo O’Higgins & 0,44 & 0,83 & 0,83 & 0,26 & 0,59 & 155 \\
\hline Combarbalá & Coquimbo & 0,58 & 0,58 & 0,75 & 0,45 & 0,59 & 156 \\
\hline María Pinto & Metropolitana de Santiago & 0,61 & 1,00 & 0,58 & 0,15 & 0,59 & 162 \\
\hline Retiro & Del Maule & 0,51 & 0,67 & 0,83 & 0,32 & 0,58 & 164 \\
\hline Lolol & Del Libertador Gral. Bernardo O'Higgins & 0,33 & 0,67 & 0,92 & 0,41 & 0,58 & 165 \\
\hline Laguna Blanca & Magallanes y de la Antártica Chilena & 0,53 & 1,00 & 0,33 & 0,43 & 0,57 & 171 \\
\hline Maule & Del Maule & 0,43 & 0,58 & 0,83 & 0,44 & 0,57 & 172 \\
\hline Florida & Del Biobío & 0,58 & 0,58 & 0,75 & 0,37 & 0,57 & 176 \\
\hline Puerto Saavedra & De la Araucanía & 0,33 & 0,83 & 0,50 & 0,61 & 0,57 & 180 \\
\hline Guaitecas & Aisén, del Gral. Carlos Ibáñez del Campo & 0,47 & 1,00 & 0,50 & 0,30 & 0,57 & 181 \\
\hline Pelarco & Del Maule & 0,09 & 0,83 & 0,83 & 0,51 & 0,57 & 182 \\
\hline Río Verde & Magallanes y de la Antártica Chilena & 0,38 & 0,67 & 0,92 & 0,30 & 0,57 & 184 \\
\hline Timaukel & Magallanes y de la Antártica Chilena & 0,59 & 0,75 & 0,92 & 0,00 & 0,56 & 186 \\
\hline Canela & Coquimbo & 0,37 & 1,00 & 0,58 & 0,30 & 0,56 & 189 \\
\hline Coelemu & Ñuble & 0,52 & 0,67 & 0,75 & 0,31 & 0,56 & 191 \\
\hline Placilla & Del Libertador Gral. Bernardo O'Higgins & 0,51 & 0,67 & 0,75 & 0,30 & 0,56 & 196 \\
\hline
\end{tabular}




\begin{tabular}{|c|c|c|c|c|c|c|c|}
\hline General Lagos & Arica y Parinacota & 0,36 & 1,00 & 0,83 & 0,02 & 0,55 & 197 \\
\hline Pemuco & Ñuble & 0,18 & 1,00 & 0,92 & 0,09 & 0,55 & 203 \\
\hline Negrete & Del Biobío & 0,17 & 0,75 & 1,00 & 0,23 & 0,54 & 205 \\
\hline Empedrado & Del Maule & 0,55 & 0,83 & 0,42 & 0,32 & 0,53 & 209 \\
\hline Curepto & Del Maule & 0,23 & 0,67 & 0,92 & 0,27 & 0,52 & 213 \\
\hline Ollagüe & Antofagasta & 0,23 & 0,67 & 0,75 & 0,42 & 0,52 & 215 \\
\hline Purén & De la Araucanía & 0,44 & 1,00 & 0,25 & 0,36 & 0,51 & 217 \\
\hline Huara & Tarapacá & 0,35 & 0,67 & 0,83 & 0,15 & 0,50 & 225 \\
\hline Perquenco & De la Araucanía & 0,49 & 1,00 & 0,00 & 0,48 & 0,49 & 228 \\
\hline Pencahue & Del Maule & 0,67 & 1,00 & 0,00 & 0,30 & 0,49 & 229 \\
\hline Torres del Paine & Magallanes y de la Antártica Chilena & 0,61 & 0,67 & 0,25 & 0,43 & 0,49 & 230 \\
\hline San Juan de la Costa & De los Lagos & 0,59 & 0,67 & 0,50 & 0,20 & 0,49 & 231 \\
\hline Coihueco & Ñuble & 0,71 & 1,00 & 0,00 & 0,25 & 0,49 & 232 \\
\hline Antuco & Del Biobío & 0,59 & 1,00 & 0,25 & 0,10 & 0,48 & 237 \\
\hline Contulmo & Del Biobío & 0,51 & 0,83 & 0,08 & 0,50 & 0,48 & 239 \\
\hline Curaco de Vélez & De los Lagos & 0,74 & 0,00 & 0,83 & 0,34 & 0,48 & 245 \\
\hline Paredones & Del Libertador Gral. Bernardo O'Higgins & 0,38 & 0,42 & 0,83 & 0,27 & 0,48 & 246 \\
\hline Queilén & De los Lagos & 0,57 & 0,67 & 0,33 & 0,33 & 0,47 & 247 \\
\hline Petorca & Valparaíso & 0,28 & 0,67 & 0,50 & 0,44 & 0,47 & 251 \\
\hline Yumbel & Del Biobío & 0,42 & 1,00 & 0,08 & 0,38 & 0,47 & 252 \\
\hline San Pedro & Metropolitana de Santiago & 0,52 & 0,00 & 0,92 & 0,33 & 0,44 & 266 \\
\hline Marchihue & Del Libertador Gral. Bernardo O’Higgins & 0,62 & 0,83 & 0,00 & 0,32 & 0,44 & 267 \\
\hline San Rafael & Del Maule & 0,46 & 1,00 & 0,00 & 0,31 & 0,44 & 268 \\
\hline Tirúa & Del Biobío & 0,30 & 1,00 & 0,08 & 0,38 & 0,44 & 269 \\
\hline Carahue & De la Araucanía & 0,32 & 0,42 & 0,58 & 0,42 & 0,44 & 276 \\
\hline Ñiquén & Ñuble & 0,74 & 0,67 & 0,00 & 0,33 & 0,43 & 277 \\
\hline Yerbas Buenas & Del Maule & 0,55 & 0,67 & 0,17 & 0,35 & 0,43 & 278 \\
\hline Longaví & Del Maule & 0,42 & 0,83 & 0,17 & 0,31 & 0,43 & 279 \\
\hline Villa Alegre & Del Maule & 0,60 & 0,00 & 0,75 & 0,39 & 0,43 & 280 \\
\hline Rauco & Del Maule & 0,50 & 0,00 & 0,92 & 0,31 & 0,43 & 283 \\
\hline Curarrehue & De la Araucanía & 0,22 & 1,00 & 0,08 & 0,42 & 0,43 & 284 \\
\hline Teodoro Schmidt & De la Araucanía & 0,42 & 0,83 & 0,08 & 0,38 & 0,43 & 285 \\
\hline
\end{tabular}




\begin{tabular}{|c|c|c|c|c|c|c|c|}
\hline Alto Biobío & Del Biobío & 0,12 & 0,67 & 0,67 & 0,24 & 0,42 & 287 \\
\hline Hualqui & Del Biobío & 0,25 & 0,83 & 0,17 & 0,45 & 0,42 & 288 \\
\hline Pinto & Ñuble & 0,45 & 0,67 & 0,25 & 0,33 & 0,42 & 289 \\
\hline Lago Verde & Aisén, del Gral. Carlos Ibáñez del Campo & 0,47 & 0,00 & 0,92 & 0,28 & 0,42 & 292 \\
\hline Alto del Carmen & Atacama & 0,71 & 0,67 & 0,00 & 0,28 & 0,42 & 293 \\
\hline La Higuera & Coquimbo & 0,62 & 0,75 & 0,00 & 0,29 & 0,41 & 294 \\
\hline Juan Fernández & Valparaíso & 0,21 & 0,83 & 0,25 & 0,35 & 0,41 & 295 \\
\hline Tortel & Aisén, del Gral. Carlos Ibáñez del Campo & 0,69 & 0,00 & 0,67 & 0,28 & 0,41 & 296 \\
\hline Quillón & Ñuble & 0,36 & 0,00 & 0,92 & 0,35 & 0,41 & 300 \\
\hline Quilleco & Del Biobío & 0,37 & 0,67 & 0,17 & 0,38 & 0,40 & 305 \\
\hline Pichidegua & Del Libertador Gral. Bernardo O’Higgins & 0,30 & 0,67 & 0,33 & 0,27 & 0,39 & 309 \\
\hline Malloa & Del Libertador Gral. Bernardo O'Higgins & 0,40 & 0,67 & 0,33 & 0,14 & 0,38 & 312 \\
\hline Galvarino & De la Araucanía & 0,49 & 0,00 & 0,67 & 0,36 & 0,38 & 313 \\
\hline Chépica & Del Libertador Gral. Bernardo O’Higgins & 0,82 & 0,00 & 0,42 & 0,28 & 0,38 & 315 \\
\hline Trehuaco & Ñuble & 0,35 & 0,00 & 0,83 & 0,32 & 0,38 & 316 \\
\hline Pelluhue & Del Maule & 0,52 & 0,67 & 0,00 & 0,26 & 0,36 & 319 \\
\hline Lumaco & De la Araucanía & 0,28 & 0,00 & 0,92 & 0,24 & 0,36 & 320 \\
\hline Ninhue & Ñuble & 0,21 & 0,00 & 0,92 & 0,29 & 0,35 & 321 \\
\hline Colbún & Del Maule & 0,40 & 0,67 & 0,00 & 0,30 & 0,34 & 322 \\
\hline San Ignacio & Ñuble & 0,29 & 0,67 & 0,00 & 0,40 & 0,34 & 323 \\
\hline Sagrada Familia & Del Maule & 0,17 & 1,00 & 0,00 & 0,17 & 0,34 & 324 \\
\hline Lonquimay & De la Araucanía & 0,26 & 0,00 & 0,67 & 0,27 & 0,30 & 331 \\
\hline Colchane & Tarapacá & 0,63 & 0,00 & 0,33 & 0,20 & 0,29 & 333 \\
\hline Quilaco & Del Biobío & 0,30 & 0,42 & 0,08 & 0,29 & 0,27 & 335 \\
\hline Melipeuco & De la Araucanía & 0,36 & 0,42 & 0,00 & 0,29 & 0,27 & 336 \\
\hline Putre & Arica y Parinacota & 0,26 & 0,00 & 0,50 & 0,29 & 0,26 & 337 \\
\hline Isla de Pascua & Valparaíso & 0,50 & 0,00 & 0,17 & 0,31 & 0,24 & 340 \\
\hline Corral & De los Ríos & 0,62 & 0,00 & 0,00 & 0,34 & 0,24 & 341 \\
\hline O'Higgins & Aisén, del Gral. Carlos Ibáñez del Campo & 0,53 & 0,00 & 0,00 & 0,32 & 0,21 & 343 \\
\hline Toltén & De la Araucanía & 0,24 & 0,00 & 0,33 & 0,26 & 0,21 & 344 \\
\hline Camarones & Arica y Parinacota & 0,32 & 0,00 & 0,25 & 0,18 & 0,19 & 345 \\
\hline
\end{tabular}

FUENTE: elaboración propia 


\section{Conclusiones}




\section{Conclusiones}

En esta tercera versión del IIGAM, hemos rescatado los esfuerzos de las mediciones anteriores y, a su vez, buscamos mejorar la coherencia y robustez del instrumento, incluyendo la revisión conceptual y la consulta a pares académicos y de la sociedad civil. Aun así, las conclusiones que nos deja esta medición se relacionan, directamente, con aquellas señaladas en las mediciones de 2016 y 2018, lo que permite reunir los hallazgos más importantes y llegar a dos conclusiones fundamentales.

Por una parte, se evidencia que los resultados del IIGAM no dependen de aspectos que, intuitivamente, podríamos pensar como explicativos. Aunque, como en versiones anteriores, se evidencia una leve tendencia entre el IIGAM y el nivel de desarrollo de las comunas, es evidente también que tanto el cumplimiento normativo, como el diseño e implementación de mecanismos participativos y buenas prácticas de transparencia, pueden ser desarrollados por municipalidades de cualquier tipo y de cualquier región.

Esto, aunque resulte una buena noticia para las municipalidades pequeñas que han hecho un esfuerzo notable, así como para las organizaciones del nivel central encargadas de apoyar y fiscalizar los aspectos de transparencia y participación ciudadana, conlleva también la necesidad de profundizar en factores menos estructurales y más administrativos y contextuales de los casos de éxito y fracaso mencionados en este estudio. Otras investigaciones desarrolladas sobre estos datos han detectado razones importantes a tener en cuenta, como la voluntad política de los alcaldes, o la iniciativa de funcionarios municipales (Hernández Bonivento, 2018).

Una segunda conclusión del presente estudio se centra en las evidentes diferencias que existen entre las variables de cumplimiento de la normativa vigente frente a aquellas que involucran iniciativa desde las municipalidades. Como se evidenció también en la medición de 2018, existe un alto cumplimiento de lo formal, pero muy bajo desarrollo de iniciativas propias de transparencia y, sobre todo, de participación pública. Esto hace evidente que el marco legal actual establece requerimientos formales, pero no incentiva la innovación a nivel municipal. Ello debería ser un punto central para nuevas investigaciones en el tema.

Por último, cerramos señalando las limitaciones de este estudio, el cual, al estar focalizado exclusivamente en el cumplimiento y la implementación de la ofer- ta institucional, deja por fuera aspectos fundamentales del gobierno abierto, como lo es la interacción con los actores sociales, sus percepciones sobre e trabajo de la municipalidad y la gestión, tanto interna (entre unidades administrativas) como externa (con otras municipalidades y el gobierno central) Esperamos, en todo caso, que este esfuerzo sea un paso más en el estudio y la comprensión de la gobernanza abierta a nivel local y que permita nuevos e innovadores acercamientos, sobre todo en un contexto de cambio y renovación institucional en el país. 


\section{Bibliograffia}




\section{Bibliografía}

Grimmelikhuijsen, S. G. \& Feeney, M. K. (2016). Developing and Testing an Integrative Framework for Open Government Adoption in Local Governments, 00 1-12. https://doi.org/10.1111/puar.12689.Developing

Hernández Bonivento, J. (2017). Gobernanza abierta a nivel local: teoría y prác tica en América Latina. En A. Naser, A. Ramírez-Alujas \& D. Rosales, Desde e gobierno abierto al Estado abierto en América Latina y el Caribe (págs. 341 352). Santiago de Chile: Cepal.

Hernández Bonivento, J. (2018). La forma y la esencia: efectos de las leyes de transparencia, acceso a la información y participación ciudadana en la gobernanza democrática local en Chile. Revista Gestión Pública, VII(2), 143-169.

Meijer, a J., Curtin, D. \& Hillebrandt, M. (2012). Open government: connecting vision and voice. International Review of Administrative Sciences, 78(1), 10 29. https://doi.org/10.1177/0020852311429533

\section{Legislación revisada}

Ley 20.285 sobre acceso a la información pública.Disponible en: https://www bcn.cl/leychile/navegar?idNorma=276363\&idParte=

Ley 20.500 sobre asociaciones y participación ciudadana en la gestión pública. Disponible en: https://www.bcn.cl/leychile/navegar?idNorma=1023143

Ley 20.730 regula el lobby y las gestiones que representen intereses particulares ante las autoridades y funcionarios.Disponible en: https://www.bcn.cl/ leychile/navegar?idNorma $=1060115$

Ley 20.880 sobre probidad en la función pública y prevención de los conflictos de intereses. Disponible en: https://www.bcn.cl/leychile/navegar?idNor $\mathrm{ma}=1086062 \&$ idParte $=9663575 \&$ idVersion=2016-09-03 


\section{Anexos}


07. Anexos

\section{Índice Institucional de Gobierno Abierto Municipal Chile 2020}

\begin{tabular}{|c|c|c|c|c|c|c|c|}
\hline Municipalidad & Región & TA & Al & PB & PP & IIGAM 2020 & P. Nal. \\
\hline La Cisterna & Metropolitana de Santiago & 0,89 & 1,00 & 0,81 & 0,60 & 0,82 & 1 \\
\hline Santa Juana & Del Biobío & 0,50 & 1,00 & 1,00 & 0,77 & 0,82 & 2 \\
\hline Laja & Del Biobío & 0,84 & 1,00 & 0,75 & 0,60 & 0,80 & 3 \\
\hline Purranque & De los Lagos & 0,73 & 1,00 & 1,00 & 0,46 & 0,80 & 4 \\
\hline Peñalolén & Metropolitana de Santiago & 0,64 & 1,00 & 0,95 & 0,59 & 0,80 & 5 \\
\hline Concepción & Del Biobío & 0,62 & 1,00 & 0,85 & 0,69 & 0,79 & 6 \\
\hline Pedro Aguirre Cerda & Metropolitana de Santiago & 0,65 & 1,00 & 0,88 & 0,63 & 0,79 & 7 \\
\hline Cochrane & Aisén, del Gral. Carlos Ibáñez del Campo & 0,79 & 1,00 & 0,83 & 0,53 & 0,79 & 8 \\
\hline La Serena & Coquimbo & 0,77 & 1,00 & 0,75 & 0,61 & 0,78 & 9 \\
\hline Traiguén & De la Araucanía & 0,63 & 1,00 & 1,00 & 0,50 & 0,78 & 10 \\
\hline Lo Barnechea & Metropolitana de Santiago & 0,86 & 1,00 & 0,75 & 0,50 & 0,78 & 11 \\
\hline Navidad & Del Libertador Gral. Bernardo O'Higgins & 0,63 & 0,83 & 1,00 & 0,63 & 0,77 & 12 \\
\hline Pucón & De la Araucanía & 0,70 & 1,00 & 1,00 & 0,37 & 0,77 & 13 \\
\hline Huechuraba & Metropolitana de Santiago & 0,77 & 1,00 & 0,92 & 0,37 & 0,76 & 14 \\
\hline Lo Espejo & Metropolitana de Santiago & 0,73 & 1,00 & 0,75 & 0,57 & 0,76 & 15 \\
\hline Tucapel & Del Biobío & 0,46 & 1,00 & 1,00 & 0,57 & 0,76 & 16 \\
\hline Molina & Del Maule & 0,83 & 1,00 & 0,83 & 0,36 & 0,76 & 17 \\
\hline Fresia & De los Lagos & 0,55 & 1,00 & 0,92 & 0,55 & 0,75 & 18 \\
\hline Caldera & Atacama & 0,43 & 1,00 & 1,00 & 0,58 & 0,75 & 19 \\
\hline San Nicolás & Ñuble & 0,45 & 1,00 & 1,00 & 0,55 & 0,75 & 20 \\
\hline El Quisco & Valparaíso & 0,64 & 1,00 & 0,92 & 0,44 & 0,75 & 21 \\
\hline Calle Larga & Valparaíso & 0,67 & 0,83 & 0,92 & 0,57 & 0,75 & 22 \\
\hline Chile Chico & Aisén, del Gral. Carlos Ibáñez del Campo & 0,65 & 1,00 & 0,92 & 0,42 & 0,75 & 23 \\
\hline Monte Patria & Coquimbo & 0,59 & 1,00 & 0,83 & 0,56 & 0,75 & 24 \\
\hline Curacautín & De la Araucanía & 0,83 & 1,00 & 0,83 & 0,32 & 0,75 & 25 \\
\hline Nacimiento & Del Biobío & 0,69 & 1,00 & 0,75 & 0,54 & 0,74 & 26 \\
\hline Providencia & Metropolitana de Santiago & 0,91 & 0,83 & 0,70 & 0,52 & 0,74 & 27 \\
\hline
\end{tabular}




\begin{tabular}{|c|c|c|c|c|c|c|c|}
\hline Lota & Del Biobío & 0,61 & 1,00 & 1,00 & 0,36 & 0,74 & 28 \\
\hline Cobquecura & Ñuble & 0,71 & 1,00 & 0,92 & 0,33 & 0,74 & 29 \\
\hline Vitacura & Metropolitana de Santiago & 0,84 & 1,00 & 0,81 & 0,28 & 0,73 & 30 \\
\hline San Antonio & Valparaíso & 0,62 & 0,75 & 0,94 & 0,62 & 0,73 & 31 \\
\hline Talca & Del Maule & 0,60 & 1,00 & 0,90 & 0,41 & 0,73 & 32 \\
\hline Ránquil & Ñuble & 0,67 & 1,00 & 0,83 & 0,39 & 0,72 & 33 \\
\hline Quilicura & Metropolitana de Santiago & 0,60 & 1,00 & 0,88 & 0,41 & 0,72 & 34 \\
\hline Cabildo & Valparaíso & 0,83 & 1,00 & 0,50 & 0,54 & 0,72 & 35 \\
\hline Parral & Del Maule & 0,61 & 1,00 & 0,83 & 0,43 & 0,72 & 36 \\
\hline Chiguayante & Del Biobío & 0,69 & 1,00 & 0,83 & 0,34 & 0,72 & 37 \\
\hline Pozo Almonte & Tarapacá & 0,80 & 0,83 & 0,92 & 0,31 & 0,72 & 38 \\
\hline Quinta Normal & Metropolitana de Santiago & 0,82 & 1,00 & 0,63 & 0,41 & 0,71 & 39 \\
\hline Coronel & Del Biobío & 0,53 & 1,00 & 0,88 & 0,45 & 0,71 & 40 \\
\hline Río Negro & De los Lagos & 0,79 & 0,67 & 1,00 & 0,37 & 0,71 & 41 \\
\hline Pirque & Metropolitana de Santiago & 0,54 & 1,00 & 0,83 & 0,45 & 0,71 & 42 \\
\hline Zapallar & Valparaíso & 0,62 & 1,00 & 0,83 & 0,37 & 0,70 & 43 \\
\hline Valparaíso & Valparaíso & 0,48 & 1,00 & 0,80 & 0,53 & 0,70 & 44 \\
\hline Maullín & De los Lagos & 0,53 & 1,00 & 1,00 & 0,27 & 0,70 & 45 \\
\hline Lago Ranco & De los Ríos & 0,58 & 0,83 & 0,83 & 0,55 & 0,70 & 46 \\
\hline Río Ibáñez & Aisén, del Gral. Carlos Ibáñez del Campo & 0,59 & 1,00 & 0,75 & 0,46 & 0,70 & 47 \\
\hline San Javier & Del Maule & 0,58 & 0,83 & 0,92 & 0,46 & 0,70 & 48 \\
\hline Coinco & Del Libertador Gral. Bernardo O'Higgins & 0,62 & 1,00 & 1,00 & 0,17 & 0,70 & 49 \\
\hline San Clemente & Del Maule & 0,61 & 0,83 & 0,83 & 0,50 & 0,70 & 50 \\
\hline Putaendo & Valparaíso & 0,62 & 1,00 & 0,92 & 0,24 & 0,69 & 51 \\
\hline Nueva Imperial & De la Araucanía & 0,31 & 1,00 & 0,92 & 0,55 & 0,69 & 52 \\
\hline San Pablo & De los Lagos & 0,62 & 0,75 & 0,92 & 0,49 & 0,69 & 53 \\
\hline Los Sauces & De la Araucanía & 0,56 & 0,83 & 1,00 & 0,38 & 0,69 & 54 \\
\hline Padre Las Casas & De la Araucanía & 0,75 & 1,00 & 0,67 & 0,36 & 0,69 & 55 \\
\hline Copiapó & Atacama & 0,66 & 0,67 & 0,81 & 0,63 & 0,69 & 56 \\
\hline Hijuelas & Valparaíso & 0,39 & 1,00 & 1,00 & 0,38 & 0,69 & 57 \\
\hline Hualaihué & De los Lagos & 0,61 & 0,75 & 1,00 & 0,40 & 0,69 & 58 \\
\hline Iquique & Tarapacá & 0,37 & 0,83 & 0,90 & 0,65 & 0,69 & 59 \\
\hline
\end{tabular}




\begin{tabular}{|c|c|c|c|c|c|c|c|}
\hline Cisnes & Aisén, del Gral. Carlos Ibáñez del Campo & 0,72 & 0,67 & 1,00 & 0,36 & 0,69 & 60 \\
\hline Cauquenes & Del Maule & 0,58 & 1,00 & 0,67 & 0,50 & 0,69 & 61 \\
\hline San Bernardo & Metropolitana de Santiago & 0,62 & 0,83 & 0,90 & 0,39 & 0,69 & 62 \\
\hline Hualañé & Del Maule & 0,63 & 1,00 & 0,83 & 0,27 & 0,68 & 63 \\
\hline San Rosendo & Del Biobío & 0,63 & 0,75 & 0,83 & 0,52 & 0,68 & 64 \\
\hline Recoleta & Metropolitana de Santiago & 0,86 & 0,67 & 0,69 & 0,51 & 0,68 & 65 \\
\hline Punitaqui & Coquimbo & 0,36 & 1,00 & 1,00 & 0,36 & 0,68 & 66 \\
\hline San Joaquín & Metropolitana de Santiago & 0,87 & 0,67 & 0,81 & 0,37 & 0,68 & 67 \\
\hline Licantén & Del Maule & 0,54 & 1,00 & 0,83 & 0,34 & 0,68 & 68 \\
\hline Quinchao & De los Lagos & 0,53 & 1,00 & 0,92 & 0,27 & 0,68 & 69 \\
\hline Los Ángeles & Del Biobío & 0,60 & 1,00 & 0,70 & 0,41 & 0,68 & 70 \\
\hline La Florida & Metropolitana de Santiago & 0,80 & 1,00 & 0,60 & 0,31 & 0,68 & 71 \\
\hline San Miguel & Metropolitana de Santiago & 0,63 & 1,00 & 0,69 & 0,38 & 0,68 & 72 \\
\hline Colina & Metropolitana de Santiago & 0,74 & 0,67 & 0,94 & 0,35 & 0,68 & 73 \\
\hline Tocopilla & Antofagasta & 0,66 & 0,83 & 0,83 & 0,37 & 0,67 & 74 \\
\hline Cartagena & Valparaíso & 0,62 & 0,75 & 0,50 & 0,81 & 0,67 & 75 \\
\hline Quillota & Valparaíso & 0,57 & 0,67 & 1,00 & 0,44 & 0,67 & 76 \\
\hline Río Hurtado & Coquimbo & 0,34 & 1,00 & 1,00 & 0,32 & 0,67 & 77 \\
\hline Arica & Arica y Parinacota & 0,59 & 0,67 & 1,00 & 0,40 & 0,66 & 78 \\
\hline Alto Hospicio & Tarapacá & 0,63 & 0,67 & 0,92 & 0,44 & 0,66 & 79 \\
\hline Paillaco & De los Ríos & 0,59 & 0,83 & 0,75 & 0,48 & 0,66 & 80 \\
\hline Curacaví & Metropolitana de Santiago & 0,74 & 0,67 & 0,92 & 0,33 & 0,66 & 81 \\
\hline El Carmen & Ñuble & 0,61 & 0,83 & 0,83 & 0,37 & 0,66 & 82 \\
\hline Linares & Del Maule & 0,51 & 1,00 & 0,75 & 0,39 & 0,66 & 83 \\
\hline Palmilla & Del Libertador Gral. Bernardo O’Higgins & 0,68 & 1,00 & 0,67 & 0,30 & 0,66 & 84 \\
\hline Quemchi & De los Lagos & 0,63 & 0,83 & 0,83 & 0,32 & 0,66 & 85 \\
\hline Collipulli & De la Araucanía & 0,59 & 0,67 & 0,92 & 0,45 & 0,66 & 86 \\
\hline Cochamó & De los Lagos & 0,76 & 0,67 & 0,83 & 0,36 & 0,65 & 87 \\
\hline La Granja & Metropolitana de Santiago & 0,73 & 0,67 & 0,69 & 0,53 & 0,65 & 88 \\
\hline Chañaral & Atacama & 0,47 & 0,67 & 1,00 & 0,47 & 0,65 & 89 \\
\hline Puerto Varas & De los Lagos & 0,74 & 0,67 & 0,75 & 0,45 & 0,65 & 90 \\
\hline Salamanca & Coquimbo & 0,63 & 1,00 & 0,33 & 0,63 & 0,65 & 91 \\
\hline
\end{tabular}




\begin{tabular}{|c|c|c|c|c|c|c|c|}
\hline Renca & Metropolitana de Santiago & 0,55 & 0,83 & 0,88 & 0,33 & 0,65 & 92 \\
\hline Litueche & Del Libertador Gral. Bernardo O’Higgins & 0,57 & 0,75 & 0,83 & 0,44 & 0,65 & 93 \\
\hline Curicó & Del Maule & 0,30 & 1,00 & 0,81 & 0,47 & 0,65 & 94 \\
\hline Santiago & Metropolitana de Santiago & 0,63 & 0,67 & 0,80 & 0,48 & 0,65 & 95 \\
\hline Ancud & De los Lagos & 0,57 & 0,83 & 0,83 & 0,34 & 0,65 & 96 \\
\hline Vallenar & Atacama & 0,43 & 0,75 & 1,00 & 0,39 & 0,64 & 97 \\
\hline Las Condes & Metropolitana de Santiago & 0,60 & 0,83 & 0,75 & 0,39 & 0,64 & 98 \\
\hline Quilpué & Valparaíso & 0,47 & 1,00 & 0,69 & 0,41 & 0,64 & 99 \\
\hline Río Claro & Del Maule & 0,59 & 0,67 & 1,00 & 0,32 & 0,64 & 100 \\
\hline San Felipe & Valparaíso & 0,75 & 0,67 & 0,75 & 0,40 & 0,64 & 101 \\
\hline Mariquina & De los Ríos & 0,71 & 1,00 & 0,50 & 0,35 & 0,64 & 102 \\
\hline Cholchol & De la Araucanía & 0,42 & 1,00 & 0,83 & 0,31 & 0,64 & 103 \\
\hline Loncoche & De la Araucanía & 0,28 & 1,00 & 1,00 & 0,28 & 0,64 & 104 \\
\hline Coquimbo & Coquimbo & 0,62 & 0,67 & 1,00 & 0,26 & 0,64 & 105 \\
\hline Penco & Del Biobío & 0,48 & 0,67 & 0,92 & 0,48 & 0,64 & 106 \\
\hline Dalcahue & De los Lagos & 0,81 & 0,67 & 0,75 & 0,32 & 0,64 & 107 \\
\hline Ovalle & Coquimbo & 0,69 & 0,42 & 0,94 & 0,50 & 0,64 & 108 \\
\hline Huasco & Atacama & 0,43 & 0,75 & 0,83 & 0,53 & 0,64 & 109 \\
\hline Cerrillos & Metropolitana de Santiago & 0,51 & 0,83 & 0,67 & 0,52 & 0,63 & 110 \\
\hline Cabo de Hornos & Magallanes y de la Antártica Chilena & 0,71 & 0,67 & 0,75 & 0,41 & 0,63 & 111 \\
\hline La Calera & Valparaíso & 0,52 & 0,75 & 0,83 & 0,42 & 0,63 & 112 \\
\hline Castro & De los Lagos & 0,85 & 1,00 & 0,17 & 0,51 & 0,63 & 113 \\
\hline Ercilla & De la Araucanía & 0,41 & 1,00 & 0,83 & 0,28 & 0,63 & 114 \\
\hline Santo Domingo & Valparaíso & 0,35 & 0,83 & 0,92 & 0,42 & 0,63 & 115 \\
\hline Coltauco & Del Libertador Gral. Bernardo O’Higgins & 0,70 & 0,42 & 1,00 & 0,39 & 0,63 & 116 \\
\hline Villarrica & De la Araucanía & 0,73 & 1,00 & 0,33 & 0,44 & 0,63 & 117 \\
\hline Gorbea & De la Araucanía & 0,74 & 0,67 & 0,75 & 0,34 & 0,62 & 118 \\
\hline Portezuelo & Ñuble & 0,78 & 0,67 & 0,67 & 0,38 & 0,62 & 119 \\
\hline Panquehue & Valparaíso & 0,64 & 0,83 & 0,75 & 0,27 & 0,62 & 120 \\
\hline Camiña & Tarapacá & 0,53 & 0,75 & 0,83 & 0,37 & 0,62 & 121 \\
\hline Ñuñoa & Metropolitana de Santiago & 0,58 & 0,83 & 0,80 & 0,28 & 0,62 & 122 \\
\hline Romeral & Del Maule & 0,58 & 0,67 & 1,00 & 0,24 & 0,62 & 123 \\
\hline
\end{tabular}




\begin{tabular}{|c|c|c|c|c|c|c|c|}
\hline San Fabián & Ñuble & 0,70 & 0,67 & 0,67 & 0,46 & 0,62 & 124 \\
\hline Calama & Antofagasta & 0,58 & 0,67 & 0,88 & 0,35 & 0,62 & 125 \\
\hline Rancagua & Del Libertador Gral. Bernardo O’Higgins & 0,68 & 0,83 & 0,60 & 0,34 & 0,62 & 126 \\
\hline Panguipulli & De los Ríos & 0,66 & 0,83 & 0,67 & 0,29 & 0,61 & 127 \\
\hline Talagante & Metropolitana de Santiago & 0,72 & 0,67 & 0,75 & 0,32 & 0,61 & 128 \\
\hline San Esteban & Valparaíso & 0,51 & 0,83 & 0,83 & 0,28 & 0,61 & 129 \\
\hline Nancagua & Del Libertador Gral. Bernardo O'Higgins & 0,47 & 0,83 & 0,67 & 0,48 & 0,61 & 130 \\
\hline Taltal & Antofagasta & 0,66 & 0,67 & 0,75 & 0,37 & 0,61 & 131 \\
\hline San Pedro de la Paz & Del Biobío & 0,46 & 1,00 & 0,44 & 0,55 & 0,61 & 132 \\
\hline Casablanca & Valparaíso & 0,58 & 1,00 & 0,50 & 0,35 & 0,61 & 133 \\
\hline Catemu & Valparaíso & 0,49 & 0,67 & 0,83 & 0,44 & 0,61 & 134 \\
\hline Puqueldón & De los Lagos & 0,45 & 1,00 & 0,67 & 0,31 & 0,61 & 135 \\
\hline Alhué & Metropolitana de Santiago & 0,50 & 1,00 & 0,50 & 0,43 & 0,61 & 136 \\
\hline Limache & Valparaíso & 0,52 & 0,67 & 0,92 & 0,32 & 0,61 & 137 \\
\hline Requínoa & Del Libertador Gral. Bernardo O'Higgins & 0,75 & 1,00 & 0,17 & 0,50 & 0,61 & 138 \\
\hline Chaitén & De los Lagos & 0,64 & 0,67 & 0,75 & 0,36 & 0,61 & 139 \\
\hline Puerto Montt & De los Lagos & 0,55 & 0,83 & 0,75 & 0,27 & 0,60 & 140 \\
\hline Lo Prado & Metropolitana de Santiago & 0,58 & 0,67 & 0,88 & 0,29 & 0,60 & 141 \\
\hline San Gregorio & Magallanes y de la Antártica Chilena & 0,49 & 0,67 & 0,92 & 0,33 & 0,60 & 142 \\
\hline La Cruz & Valparaíso & 0,31 & 0,83 & 0,92 & 0,34 & 0,60 & 143 \\
\hline Peralillo & Del Libertador Gral. Bernardo O’Higgins & 0,56 & 0,67 & 0,83 & 0,34 & 0,60 & 144 \\
\hline Freire & De la Araucanía & 0,57 & 0,67 & 0,83 & 0,32 & 0,60 & 145 \\
\hline Olivar & Del Libertador Gral. Bernardo O’Higgins & 0,63 & 0,67 & 0,83 & 0,26 & 0,60 & 146 \\
\hline Tomé & Del Biobío & 0,79 & 0,67 & 0,58 & 0,35 & 0,60 & 147 \\
\hline Chanco & Del Maule & 0,39 & 1,00 & 0,92 & 0,09 & 0,60 & 148 \\
\hline Chimbarongo & Del Libertador Gral. Bernardo O'Higgins & 0,66 & 0,67 & 0,75 & 0,31 & 0,60 & 149 \\
\hline Pitrufquén & De la Araucanía & 0,44 & 0,75 & 0,83 & 0,36 & 0,60 & 150 \\
\hline Tierra Amarilla & Atacama & 0,39 & 0,67 & 0,92 & 0,40 & 0,59 & 151 \\
\hline Punta Arenas & Magallanes y de la Antártica Chilena & 0,88 & 0,67 & 0,56 & 0,26 & 0,59 & 152 \\
\hline Macul & Metropolitana de Santiago & 0,46 & 0,67 & 0,94 & 0,31 & 0,59 & 153 \\
\hline Nogales & Valparaíso & 0,63 & 0,67 & 0,83 & 0,25 & 0,59 & 154 \\
\hline Pumanque & Del Libertador Gral. Bernardo O’Higgins & 0,44 & 0,83 & 0,83 & 0,26 & 0,59 & 155 \\
\hline
\end{tabular}




\begin{tabular}{|c|c|c|c|c|c|c|c|}
\hline Combarbalá & Coquimbo & 0,58 & 0,58 & 0,75 & 0,45 & 0,59 & 156 \\
\hline Quinta de Tilcoco & Del Libertador Gral. Bernardo O'Higgins & 0,30 & 0,83 & 0,92 & 0,31 & 0,59 & 157 \\
\hline Mulchén & Del Biobío & 0,47 & 0,83 & 0,67 & 0,38 & 0,59 & 158 \\
\hline Arauco & Del Biobío & 0,70 & 1,00 & 0,08 & 0,57 & 0,59 & 159 \\
\hline San Fernando & Del Libertador Gral. Bernardo O’Higgins & 0,39 & 1,00 & 0,67 & 0,30 & 0,59 & 160 \\
\hline Andacollo & Coquimbo & 0,34 & 0,67 & 1,00 & 0,35 & 0,59 & 161 \\
\hline María Pinto & Metropolitana de Santiago & 0,61 & 1,00 & 0,58 & 0,15 & 0,59 & 162 \\
\hline Temuco & De la Araucanía & 0,68 & 1,00 & 0,00 & 0,64 & 0,58 & 163 \\
\hline Retiro & Del Maule & 0,51 & 0,67 & 0,83 & 0,32 & 0,58 & 164 \\
\hline Lolol & Del Libertador Gral. Bernardo O'Higgins & 0,33 & 0,67 & 0,92 & 0,41 & 0,58 & 165 \\
\hline Calbuco & De los Lagos & 0,73 & 1,00 & 0,25 & 0,34 & 0,58 & 166 \\
\hline Angol & De la Araucanía & 0,42 & 0,67 & 0,92 & 0,31 & 0,58 & 167 \\
\hline Cerro Navia & Metropolitana de Santiago & 0,69 & 0,83 & 0,31 & 0,47 & 0,58 & 168 \\
\hline Quintero & Valparaíso & 0,40 & 0,67 & 0,83 & 0,41 & 0,58 & 169 \\
\hline Los Vilos & Coquimbo & 0,66 & 1,00 & 0,08 & 0,55 & 0,57 & 170 \\
\hline Laguna Blanca & Magallanes y de la Antártica Chilena & 0,53 & 1,00 & 0,33 & 0,43 & 0,57 & 171 \\
\hline Maule & Del Maule & 0,43 & 0,58 & 0,83 & 0,44 & 0,57 & 172 \\
\hline La Pintana & Metropolitana de Santiago & 0,49 & 0,67 & 0,75 & 0,39 & 0,57 & 173 \\
\hline Estación Central & Metropolitana de Santiago & 0,42 & 1,00 & 0,38 & 0,49 & 0,57 & 174 \\
\hline Llanquihue & De los Lagos & 0,37 & 0,67 & 1,00 & 0,25 & 0,57 & 175 \\
\hline Florida & Del Biobío & 0,58 & 0,58 & 0,75 & 0,37 & 0,57 & 176 \\
\hline La Estrella & Del Libertador Gral. Bernardo O'Higgins & 0,51 & 0,58 & 0,83 & 0,36 & 0,57 & 177 \\
\hline Santa María & Valparaíso & 0,54 & 1,00 & 0,17 & 0,57 & 0,57 & 178 \\
\hline Rengo & Del Libertador Gral. Bernardo O’Higgins & 0,55 & 0,58 & 0,75 & 0,39 & 0,57 & 179 \\
\hline Puerto Saavedra & De la Araucanía & 0,33 & 0,83 & 0,50 & 0,61 & 0,57 & 180 \\
\hline Guaitecas & Aisén, del Gral. Carlos Ibáñez del Campo & 0,47 & 1,00 & 0,50 & 0,30 & 0,57 & 181 \\
\hline Pelarco & Del Maule & 0,09 & 0,83 & 0,83 & 0,51 & 0,57 & 182 \\
\hline Constitución & Del Maule & 0,35 & 0,67 & 0,92 & 0,33 & 0,57 & 183 \\
\hline Río Verde & Magallanes y de la Antártica Chilena & 0,38 & 0,67 & 0,92 & 0,30 & 0,57 & 184 \\
\hline Hualpén & Del Biobío & 0,56 & 0,58 & 0,69 & 0,43 & 0,56 & 185 \\
\hline Timaukel & Magallanes y de la Antártica Chilena & 0,59 & 0,75 & 0,92 & 0,00 & 0,56 & 186 \\
\hline Puyehue & De los Lagos & 0,70 & 0,67 & 0,50 & 0,39 & 0,56 & 187 \\
\hline
\end{tabular}




\begin{tabular}{|c|c|c|c|c|c|c|c|}
\hline Lanco & De los Ríos & 0,65 & 0,83 & 0,33 & 0,44 & 0,56 & 188 \\
\hline Canela & Coquimbo & 0,37 & 1,00 & 0,58 & 0,30 & 0,56 & 189 \\
\hline Pichilemu & Del Libertador Gral. Bernardo O'Higgins & 0,54 & 1,00 & 0,42 & 0,29 & 0,56 & 190 \\
\hline Coelemu & Ñuble & 0,52 & 0,67 & 0,75 & 0,31 & 0,56 & 191 \\
\hline Santa Cruz & Del Libertador Gral. Bernardo O’Higgins & 0,54 & 0,67 & 0,83 & 0,20 & 0,56 & 192 \\
\hline Cabrero & Del Biobío & 0,49 & 0,83 & 0,33 & 0,57 & 0,56 & 193 \\
\hline Maipú & Metropolitana de Santiago & 0,62 & 1,00 & 0,00 & 0,61 & 0,56 & 194 \\
\hline San Vicente de Tagua Tagua & Del Libertador Gral. Bernardo O’Higgins & 0,75 & 0,67 & 0,42 & 0,39 & 0,56 & 195 \\
\hline Placilla & Del Libertador Gral. Bernardo O'Higgins & 0,51 & 0,67 & 0,75 & 0,30 & 0,56 & 196 \\
\hline General Lagos & Arica y Parinacota & 0,36 & 1,00 & 0,83 & 0,02 & 0,55 & 197 \\
\hline Papudo & Valparaíso & 0,47 & 0,67 & 0,83 & 0,23 & 0,55 & 198 \\
\hline Lampa & Metropolitana de Santiago & 0,43 & 0,67 & 0,75 & 0,35 & 0,55 & 199 \\
\hline Puente Alto & Metropolitana de Santiago & 0,47 & 0,67 & 0,75 & 0,30 & 0,55 & 200 \\
\hline Concón & Valparaíso & 0,57 & 0,67 & 0,67 & 0,29 & 0,55 & 201 \\
\hline Bulnes & Ñuble & 0,59 & 1,00 & 0,08 & 0,52 & 0,55 & 202 \\
\hline Pemuco & Ñuble & 0,18 & 1,00 & 0,92 & 0,09 & 0,55 & 203 \\
\hline San José de Maipo & Metropolitana de Santiago & 0,43 & 0,67 & 0,75 & 0,31 & 0,54 & 204 \\
\hline Negrete & Del Biobío & 0,17 & 0,75 & 1,00 & 0,23 & 0,54 & 205 \\
\hline Los Álamos & Del Biobío & 0,22 & 0,67 & 0,92 & 0,35 & 0,54 & 206 \\
\hline Osorno & De los Lagos & 0,76 & 0,67 & 0,25 & 0,46 & 0,53 & 207 \\
\hline La Ligua & Valparaíso & 0,28 & 0,67 & 0,83 & 0,35 & 0,53 & 208 \\
\hline Empedrado & Del Maule & 0,55 & 0,83 & 0,42 & 0,32 & 0,53 & 209 \\
\hline María Elena & Antofagasta & 0,36 & 1,00 & 0,50 & 0,25 & 0,53 & 210 \\
\hline Teno & Del Maule & 0,60 & 1,00 & 0,08 & 0,42 & 0,53 & 211 \\
\hline Machalí & Del Libertador Gral. Bernardo O'Higgins & 0,66 & 0,75 & 0,25 & 0,42 & 0,52 & 212 \\
\hline Curepto & Del Maule & 0,23 & 0,67 & 0,92 & 0,27 & 0,52 & 213 \\
\hline Vichuquén & Del Maule & 0,44 & 0,58 & 0,75 & 0,30 & 0,52 & 214 \\
\hline Ollagüe & Antofagasta & 0,23 & 0,67 & 0,75 & 0,42 & 0,52 & 215 \\
\hline Cunco & De la Araucanía & 0,56 & 0,75 & 0,42 & 0,33 & 0,51 & 216 \\
\hline Purén & De la Araucanía & 0,44 & 1,00 & 0,25 & 0,36 & 0,51 & 217 \\
\hline Paihuano & Coquimbo & 0,29 & 0,67 & 0,83 & 0,25 & 0,51 & 218 \\
\hline Llaillay & Valparaíso & 0,19 & 0,67 & 0,92 & 0,26 & 0,51 & 219 \\
\hline
\end{tabular}




\begin{tabular}{|c|c|c|c|c|c|c|c|}
\hline Graneros & Del Libertador Gral. Bernardo O'Higgins & 0,37 & 1,00 & 0,33 & 0,33 & 0,51 & 220 \\
\hline Viña del Mar & Valparaíso & 0,38 & 1,00 & 0,20 & 0,45 & 0,51 & 221 \\
\hline Talcahuano & Del Biobío & 0,65 & 0,67 & 0,25 & 0,45 & 0,51 & 222 \\
\hline Pudahuel & Metropolitana de Santiago & 0,61 & 0,83 & 0,20 & 0,37 & 0,51 & 223 \\
\hline Algarrobo & Valparaíso & 0,35 & 0,67 & 0,75 & 0,24 & 0,50 & 224 \\
\hline Paine & Metropolitana de Santiago & 0,53 & 1,00 & 0,25 & 0,23 & 0,50 & 225 \\
\hline Huara & Tarapacá & 0,35 & 0,67 & 0,83 & 0,15 & 0,50 & 226 \\
\hline San Ramón & Metropolitana de Santiago & 0,42 & 0,83 & 0,38 & 0,37 & 0,50 & 227 \\
\hline Los Andes & Valparaíso & 0,59 & 0,67 & 0,67 & 0,05 & 0,49 & 228 \\
\hline Perquenco & De la Araucanía & 0,49 & 1,00 & 0,00 & 0,48 & 0,49 & 229 \\
\hline Pencahue & Del Maule & 0,67 & 1,00 & 0,00 & 0,30 & 0,49 & 230 \\
\hline Torres del Paine & Magallanes y de la Antártica Chilena & 0,61 & 0,67 & 0,25 & 0,43 & 0,49 & 231 \\
\hline San Juan de la Costa & De los Lagos & 0,59 & 0,67 & 0,50 & 0,20 & 0,49 & 232 \\
\hline Coihueco & Ñuble & 0,71 & 1,00 & 0,00 & 0,25 & 0,49 & 233 \\
\hline Tiltil & Metropolitana de Santiago & 0,59 & 0,00 & 1,00 & 0,35 & 0,49 & 234 \\
\hline Peumo & Del Libertador Gral. Bernardo O'Higgins & 0,57 & 1,00 & 0,00 & 0,37 & 0,49 & 235 \\
\hline EL Tabo & Valparaíso & 0,53 & 1,00 & 0,17 & 0,24 & 0,48 & 236 \\
\hline La Unión & De los Ríos & 0,74 & 0,67 & 0,17 & 0,36 & 0,48 & 237 \\
\hline Antuco & Del Biobío & 0,59 & 1,00 & 0,25 & 0,10 & 0,48 & 238 \\
\hline Conchalí & Metropolitana de Santiago & 0,81 & 0,00 & 0,81 & 0,31 & 0,48 & 239 \\
\hline Contulmo & Del Biobío & 0,51 & 0,83 & 0,08 & 0,50 & 0,48 & 240 \\
\hline Porvenir & Magallanes y de la Antártica Chilena & 0,47 & 0,42 & 0,75 & 0,29 & 0,48 & 241 \\
\hline Melipilla & Metropolitana de Santiago & 0,72 & 0,00 & 0,81 & 0,39 & 0,48 & 242 \\
\hline Olmué & Valparaíso & 0,32 & 0,67 & 0,67 & 0,26 & 0,48 & 243 \\
\hline Chillán Viejo & Ñuble & 0,56 & 0,67 & 0,25 & 0,44 & 0,48 & 244 \\
\hline Codegua & Del Libertador Gral. Bernardo O'Higgins & 0,61 & 0,67 & 0,17 & 0,46 & 0,48 & 245 \\
\hline Curaco de Vélez & De los Lagos & 0,74 & 0,00 & 0,83 & 0,34 & 0,48 & 246 \\
\hline Paredones & Del Libertador Gral. Bernardo O’Higgins & 0,38 & 0,42 & 0,83 & 0,27 & 0,48 & 247 \\
\hline Queilén & De los Lagos & 0,57 & 0,67 & 0,33 & 0,33 & 0,47 & 248 \\
\hline Pica & Tarapacá & 0,64 & 0,83 & 0,08 & 0,33 & 0,47 & 249 \\
\hline Curanilahue & Del Biobío & 0,28 & 0,67 & 0,50 & 0,44 & 0,47 & 250 \\
\hline Illapel & Coquimbo & 0,47 & 0,42 & 0,58 & 0,41 & 0,47 & 251 \\
\hline
\end{tabular}




\begin{tabular}{|c|c|c|c|c|c|c|c|}
\hline Petorca & Valparaíso & 0,28 & 0,67 & 0,50 & 0,44 & 0,47 & 252 \\
\hline Yumbel & Del Biobío & 0,42 & 1,00 & 0,08 & 0,38 & 0,47 & 253 \\
\hline Santa Bárbara & Del Biobío & 0,57 & 0,67 & 0,25 & 0,38 & 0,47 & 254 \\
\hline Puerto Aisén & Aisén, del Gral. Carlos Ibáñez del Campo & 0,45 & 0,67 & 0,42 & 0,31 & 0,46 & 255 \\
\hline Diego de Almagro & Atacama & 0,47 & 0,67 & 0,50 & 0,21 & 0,46 & 256 \\
\hline Mejillones & Antofagasta & 0,78 & 0,42 & 0,33 & 0,31 & 0,46 & 257 \\
\hline Buin & Metropolitana de Santiago & 0,53 & 0,00 & 1,00 & 0,30 & 0,46 & 258 \\
\hline Antofagasta & Antofagasta & 0,62 & 0,83 & 0,05 & 0,32 & 0,46 & 259 \\
\hline Coyhaique & Aisén, del Gral. Carlos Ibáñez del Campo & 0,66 & 0,00 & 0,83 & 0,32 & 0,45 & 260 \\
\hline Doñihue & Del Libertador Gral. Bernardo O'Higgins & 0,75 & 0,67 & 0,08 & 0,32 & 0,45 & 261 \\
\hline Vilcún & De la Araucanía & 0,56 & 0,58 & 0,25 & 0,42 & 0,45 & 262 \\
\hline Puchuncaví & Valparaíso & 0,44 & 0,83 & 0,17 & 0,37 & 0,45 & 263 \\
\hline Las Cabras & Del Libertador Gral. Bernardo O'Higgins & 0,75 & 0,67 & 0,08 & 0,30 & 0,45 & 264 \\
\hline Vicuña & Coquimbo & 0,47 & 0,00 & 0,83 & 0,48 & 0,45 & 265 \\
\hline Los Muermos & De los Lagos & 0,68 & 0,42 & 0,33 & 0,36 & 0,45 & 266 \\
\hline San Pedro & Metropolitana de Santiago & 0,52 & 0,00 & 0,92 & 0,33 & 0,44 & 267 \\
\hline Marchihue & Del Libertador Gral. Bernardo O'Higgins & 0,62 & 0,83 & 0,00 & 0,32 & 0,44 & 268 \\
\hline San Rafael & Del Maule & 0,46 & 1,00 & 0,00 & 0,31 & 0,44 & 269 \\
\hline Tirúa & Del Biobío & 0,30 & 1,00 & 0,08 & 0,38 & 0,44 & 270 \\
\hline Padre Hurtado & Metropolitana de Santiago & 0,61 & 0,67 & 0,25 & 0,24 & 0,44 & 271 \\
\hline Sierra Gorda & Antofagasta & 0,58 & 1,00 & 0,08 & 0,09 & 0,44 & 272 \\
\hline Peñaflor & Metropolitana de Santiago & 0,47 & 0,75 & 0,17 & 0,37 & 0,44 & 273 \\
\hline Lautaro & De la Araucanía & 0,68 & 0,67 & 0,08 & 0,32 & 0,44 & 274 \\
\hline El Bosque & Metropolitana de Santiago & 0,48 & 0,67 & 0,13 & 0,47 & 0,44 & 275 \\
\hline Lebu & Del Biobío & 0,72 & 0,00 & 0,75 & 0,27 & 0,44 & 276 \\
\hline Carahue & De la Araucanía & 0,32 & 0,42 & 0,58 & 0,42 & 0,44 & 277 \\
\hline Ñiquén & Ñuble & 0,74 & 0,67 & 0,00 & 0,33 & 0,43 & 278 \\
\hline Yerbas Buenas & Del Maule & 0,55 & 0,67 & 0,17 & 0,35 & 0,43 & 279 \\
\hline Longaví & Del Maule & 0,42 & 0,83 & 0,17 & 0,31 & 0,43 & 280 \\
\hline Villa Alegre & Del Maule & 0,60 & 0,00 & 0,75 & 0,39 & 0,43 & 281 \\
\hline Puerto Natales & Magallanes y de la Antártica Chilena & 0,67 & 0,75 & 0,00 & 0,31 & 0,43 & 282 \\
\hline Chonchi & De los Lagos & 0,68 & 0,67 & 0,00 & 0,38 & 0,43 & 283 \\
\hline
\end{tabular}




\begin{tabular}{|c|c|c|c|c|c|c|c|}
\hline Rauco & Del Maule & 0,50 & 0,00 & 0,92 & 0,31 & 0,43 & 284 \\
\hline Curarrehue & De la Araucanía & 0,22 & 1,00 & 0,08 & 0,42 & 0,43 & 285 \\
\hline Teodoro Schmidt & De la Araucanía & 0,42 & 0,83 & 0,08 & 0,38 & 0,43 & 286 \\
\hline El Monte & Metropolitana de Santiago & 0,51 & 0,67 & 0,00 & 0,53 & 0,43 & 287 \\
\hline Alto Biobío & Del Biobío & 0,12 & 0,67 & 0,67 & 0,24 & 0,42 & 288 \\
\hline Hualqui & Del Biobío & 0,25 & 0,83 & 0,17 & 0,45 & 0,42 & 289 \\
\hline Pinto & Ñuble & 0,45 & 0,67 & 0,25 & 0,33 & 0,42 & 290 \\
\hline Freirina & Atacama & 0,27 & 0,75 & 0,25 & 0,41 & 0,42 & 291 \\
\hline Chillán & Ñuble & 0,49 & 0,42 & 0,44 & 0,34 & 0,42 & 292 \\
\hline Lago Verde & Aisén, del Gral. Carlos Ibáñez del Campo & 0,47 & 0,00 & 0,92 & 0,28 & 0,42 & 293 \\
\hline Alto del Carmen & Atacama & 0,71 & 0,67 & 0,00 & 0,28 & 0,42 & 294 \\
\hline La Higuera & Coquimbo & 0,62 & 0,75 & 0,00 & 0,29 & 0,41 & 295 \\
\hline Juan Fernández & Valparaíso & 0,21 & 0,83 & 0,25 & 0,35 & 0,41 & 296 \\
\hline Tortel & Aisén, del Gral. Carlos Ibáñez del Campo & 0,69 & 0,00 & 0,67 & 0,28 & 0,41 & 297 \\
\hline Isla de Maipo & Metropolitana de Santiago & 0,53 & 0,67 & 0,08 & 0,35 & 0,41 & 298 \\
\hline Victoria & De la Araucanía & 0,43 & 0,67 & 0,08 & 0,45 & 0,41 & 299 \\
\hline San Pedro de Atacama & Antofagasta & 0,26 & 0,42 & 0,67 & 0,28 & 0,41 & 300 \\
\hline Quillón & Ñuble & 0,36 & 0,00 & 0,92 & 0,35 & 0,41 & 301 \\
\hline Yungay & Ñuble & 0,51 & 0,00 & 0,75 & 0,37 & 0,41 & 302 \\
\hline Calera de Tango & Metropolitana de Santiago & 0,54 & 0,42 & 0,33 & 0,33 & 0,40 & 303 \\
\hline Palena & De los Lagos & 0,59 & 0,67 & 0,00 & 0,36 & 0,40 & 304 \\
\hline Rinconada & Valparaíso & 0,45 & 0,00 & 1,00 & 0,13 & 0,40 & 305 \\
\hline Quilleco & Del Biobío & 0,37 & 0,67 & 0,17 & 0,38 & 0,40 & 306 \\
\hline Los Lagos & De los Ríos & 0,61 & 0,00 & 0,58 & 0,39 & 0,40 & 307 \\
\hline Máfil & De los Ríos & 0,56 & 0,67 & 0,00 & 0,34 & 0,39 & 308 \\
\hline Villa Alemana & Valparaíso & 0,61 & 0,67 & 0,00 & 0,29 & 0,39 & 309 \\
\hline Pichidegua & Del Libertador Gral. Bernardo O’Higgins & 0,30 & 0,67 & 0,33 & 0,27 & 0,39 & 310 \\
\hline Frutillar & De los Lagos & 0,47 & 0,67 & 0,00 & 0,40 & 0,39 & 311 \\
\hline Quellón & De los Lagos & 0,43 & 0,67 & 0,17 & 0,28 & 0,39 & 312 \\
\hline Malloa & Del Libertador Gral. Bernardo O’Higgins & 0,40 & 0,67 & 0,33 & 0,14 & 0,38 & 313 \\
\hline Galvarino & De la Araucanía & 0,49 & 0,00 & 0,67 & 0,36 & 0,38 & 314 \\
\hline Futaleufú & De los Lagos & 0,44 & 0,67 & 0,17 & 0,24 & 0,38 & 315 \\
\hline
\end{tabular}




\begin{tabular}{|c|c|c|c|c|c|c|c|}
\hline Chépica & Del Libertador Gral. Bernardo O'Higgins & 0,82 & 0,00 & 0,42 & 0,28 & 0,38 & 316 \\
\hline Trehuaco & Ñuble & 0,35 & 0,00 & 0,83 & 0,32 & 0,38 & 317 \\
\hline Puerto Octay & De los Lagos & 0,38 & 0,83 & 0,00 & 0,26 & 0,37 & 318 \\
\hline Cañete & Del Biobío & 0,33 & 0,67 & 0,08 & 0,37 & 0,36 & 319 \\
\hline Pelluhue & Del Maule & 0,52 & 0,67 & 0,00 & 0,26 & 0,36 & 320 \\
\hline Lumaco & De la Araucanía & 0,28 & 0,00 & 0,92 & 0,24 & 0,36 & 321 \\
\hline Ninhue & Ñuble & 0,21 & 0,00 & 0,92 & 0,29 & 0,35 & 322 \\
\hline Colbún & Del Maule & 0,40 & 0,67 & 0,00 & 0,30 & 0,34 & 323 \\
\hline San Ignacio & Ñuble & 0,29 & 0,67 & 0,00 & 0,40 & 0,34 & 324 \\
\hline Sagrada Familia & Del Maule & 0,17 & 1,00 & 0,00 & 0,17 & 0,34 & 325 \\
\hline Quirihue & Ñuble & 0,35 & 0,42 & 0,33 & 0,25 & 0,34 & 326 \\
\hline Río Bueno & De los Ríos & 0,46 & 0,00 & 0,50 & 0,34 & 0,33 & 327 \\
\hline Renaico & De la Araucanía & 0,38 & 0,67 & 0,00 & 0,25 & 0,32 & 328 \\
\hline Primavera & Magallanes y de la Antártica Chilena & 0,53 & 0,42 & 0,00 & 0,31 & 0,31 & 329 \\
\hline La Reina & Metropolitana de Santiago & 0,60 & 0,00 & 0,38 & 0,26 & 0,31 & 330 \\
\hline Futrono & De los Ríos & 0,27 & 0,75 & 0,08 & 0,10 & 0,30 & 331 \\
\hline Lonquimay & De la Araucanía & 0,26 & 0,00 & 0,67 & 0,27 & 0,30 & 332 \\
\hline Mostazal & Del Libertador Gral. Bernardo O'Higgins & 0,67 & 0,00 & 0,25 & 0,27 & 0,30 & 333 \\
\hline Colchane & Tarapacá & 0,63 & 0,00 & 0,33 & 0,20 & 0,29 & 334 \\
\hline Valdivia & De los Ríos & 0,68 & 0,00 & 0,13 & 0,31 & 0,28 & 335 \\
\hline Quilaco & Del Biobío & 0,30 & 0,42 & 0,08 & 0,29 & 0,27 & 336 \\
\hline Melipeuco & De la Araucanía & 0,36 & 0,42 & 0,00 & 0,29 & 0,27 & 337 \\
\hline Putre & Arica y Parinacota & 0,26 & 0,00 & 0,50 & 0,29 & 0,26 & 338 \\
\hline San Carlos & Ñuble & 0,40 & 0,00 & 0,25 & 0,40 & 0,26 & 339 \\
\hline Isla de Pascua & Valparaíso & 0,50 & 0,00 & 0,17 & 0,31 & 0,24 & 340 \\
\hline Corral & De los Ríos & 0,62 & 0,00 & 0,00 & 0,34 & 0,24 & 341 \\
\hline Independencia & Metropolitana de Santiago & 0,29 & 0,00 & 0,31 & 0,33 & 0,23 & 342 \\
\hline O’Higgins & Aisén, del Gral. Carlos Ibáñez del Campo & 0,53 & 0,00 & 0,00 & 0,32 & 0,21 & 343 \\
\hline Toltén & De la Araucanía & 0,24 & 0,00 & 0,33 & 0,26 & 0,21 & 344 \\
\hline Camarones & Arica y Parinacota & 0,32 & 0,00 & 0,25 & 0,18 & 0,19 & 345 \\
\hline
\end{tabular}


Este libro se terminó de imprimir

en Santiago de Chile,
agosto de 2021

Teléfono: 222238100 / ril@ rileditores.com

Se utilizó tecnologia de étitima generación que reduce
el impacto medioambiental, pues ocupa estrictamente

el impacto medioambiental, pues ocupa estriciamente
el papel necesario para su produccion, y se aplicaron

el papel necesario para su producción y se aplicaron
altos estándares parar la gestión y reciclaje de desechos

en toda la a cadena de produccioion. 
En los últimos años, la legislación chilena ha introducido varias reformas que buscaron acercar la administración pública a la ciudadanía, a través de mecanismos formales de transparencia, acceso a la información, probidad y participación ciudadana. Buscando hacer un seguimiento de los niveles de cumplimiento de las 345 municipalidades del país, el Instituto Chileno de Estudios Municipales de la Universidad Autónoma de Chile se complace en presentar la tercera versión del Índice Institucional de Gobierno Abierto Municipal - IIGAM, medición realizada durante el año 2020 y que busca observar los avances y los desafíos de la implementación de dichos mecanismos a nivel municipal en el país. Con una metodología renovada, y rescatando lo avanzado en esfuerzos anteriores, este nuevo Índice detalla avances en el cumplimiento formal, pero un vacío importante en temas de innovación pública a nivel local, un área de gran importancia para alcanzar una administración cada vez más abierta y responsable.

RiL editores

